\title{
Losing Life and Livelihood: A Systematic Review and Meta- Analysis of Unemployment and All-Cause Mortality
}

\author{
David J. Roelfs, \\ Department of Sociology, Stony Brook University, Stony Brook NY USA \\ Eran Shor, \\ Department of Sociology, McGill University, Montreal, Quebec, Canada \\ Karina W. Davidson, and \\ Department of Medicine and Psychiatry, Columbia University, New York NY USA \\ Joseph E. Schwartz \\ Department of Psychiatry and Behavioral Medicine, Stony Brook University, Stony Brook NY USA
}

\begin{abstract}
Unemployment rates in the United States remain near a 25-year high and global unemployment is rising. Previous studies have shown that unemployed persons have an increased risk of death, but the magnitude of the risk and moderating factors have not been explored. The study is a randomeffects meta-analysis and meta-regression designed to assess the association between unemployment and all-cause mortality among working-age persons. We extracted 235 mortality risk estimates from 42 studies, providing data on more than 20 million persons. The mean hazard ratio (HR) for mortality was 1.63 among HRs adjusted for age and additional covariates. The mean effect was higher for men than for women. Unemployment was associated with an increased mortality risk for those in their early and middle careers, but less for those in their late-career. The risk of death was highest during the first 10 years of follow up, but decreased subsequently. The mean HR was $24 \%$ lower among the subset of studies controlling for health-related behaviors. Public health initiatives could target unemployed persons for more aggressive cardiovascular screening and interventions aimed at reducing risk-taking behaviors.
\end{abstract}

\section{Keywords}

Unemployment; All-cause Mortality; Meta-analysis; Meta-regression; Systematic Review;

Psychosocial Stress; health behaviours

According to the United States Department of Labor, the US unemployment rate was 9.6\% in August 2010 (compared to 5.8\% in July 2008), remaining near its highest level in 25 years (United States Department of Labor, 2010). As of July 2010, the unemployment rate was 7.1\% in Canada, 5.3\% in Australia, 4.9\% in Japan, 9.6\% in France, $7.3 \%$ in Germany, $8.5 \%$ in Italy, 4.4\% (June 2010) in the Netherlands, $8.4 \%$ in Sweden, and 7.8\% (May 2010)

(C) 2011 Elsevier Ltd. All rights reserved.

Contact information for corresponding author (David Roelfs): S-401 SBS Building Department of Sociology Stony Brook University Stony Brook, NY 11794-4356.

Publisher's Disclaimer: This is a PDF file of an unedited manuscript that has been accepted for publication. As a service to our customers we are providing this early version of the manuscript. The manuscript will undergo copyediting, typesetting, and review of the resulting proof before it is published in its final citable form. Please note that during the production process errors may be discovered which could affect the content, and all legal disclaimers that apply to the journal pertain. 
in the United Kingdom (U.S. Bureau of Labor Statistics, 2010). Even before the 2008-2009 economic crisis, the United Nations International Labor Organization estimated that unemployment had reached a historical high in 2006 (United Nations News Centre, 2007). The London Times estimated that, as a result of the current economic crisis, the number of unemployed worldwide could climb further, from 179 million in 2007 to 230 million (Mortished, 2009). This recent rise makes understanding the health effects of unemployment particularly important.

Over the last 4 decades the study of unemployment and its association with health and mortality has expanded significantly (see Hanisch, 1999 for an early comprehensive review on unemployment research). Whether unemployment is causally related to mortality remains an open question (Urban Janlert, 1997; Lundin, Lundberg, Hallsten, Ottoson, \& Hemmingsson, 2010; Martikainen, 1990; Martikainen, Maki, \& Jantti, 2007; Moser, Goldblatt, Fox, \& Jones, 1987), and recent research has begun to focus on possible confounding, mediating, and moderating factors.

One important line of research has been exploring the role of health behaviors such as smoking and alcohol consumption on unemployment and health. This research has generated two major hypotheses regarding the relationship between unemployment and health behaviors. The first, the "coping hypothesis", argues that unemployment causes adverse changes in health behaviors, which in turn lead to deterioration of health (e.g. Hammarstrom, 1994). The second, a "latent sickness hypothesis", suggests that the unemployment-mortality association is spurious because pre-existing health behaviors lead to both unemployment and adverse health (e.g. Jusot, Khlat, Rochereau, \& Sermet, 2008).

A second important line of research explores the role of macro-level economic factors in the unemployment-health relationship. National welfare and unemployment policies are thought to play a moderating role, with the negative effects of unemployment being substantially reduced in nations with more generous financial support systems (Bambra \& Eikemo, 2009; U. Gerdtham \& Ruhm, 2006; Jantti, Martikainen, \& Valkonen, 2000; Stuckler, Basu, Suhrcke, Coutts, \& McKee, 2009). In addition, some researchers have focused on regional and national unemployment rates as a moderator, finding harsher personal unemployment effects when there are relatively few others who are also unemployed (U. Gerdtham \& Johannesson, 2005; Martikainen et al., 2007; Martikainen \& Valkonen, 1996; Novo, Hammarstrom, \& Janlert, 2001). Others have reported a seemingly paradoxical relationship, noting that dangerous health behaviors decline when the unemployment rate is high (e.g. Ruhm, 2000).

Despite its extensiveness, only one systematic review of the unemployment literature has been conducted (see Jin, Shah, \& Svoboda, 1995). This review, however, was qualitative in nature and examined multiple health outcomes. A systematic, quantitative review of the association between unemployment and mortality, arguably the most important outcome, has not yet been conducted. While most studies found that unemployment is associated with decreased longevity, there is no consensus on the magnitude of the association for any subgroup population, and reported relative risks range from 0.68 to 4.83 . Furthermore, there is little consensus with respect to which of the possible mediating, moderating, and confounding variables matter most. Meta-analysis is well suited to address this important research problem. Ample cross-study variability now exists to analyze subgroups and to assess the effects of potential confounding, mediating, and moderating variables.

\section{Mediating and Confounding Health Factors in Unemployment Research}

Early work on the association between unemployment and mortality suggested that the relationship is causal (Moser et al., 1987). More recent work, however, has called this into 
question and the issue of causation remains unsettled (Martikainen, 1990; Martikainen et al., 2007). Many studies, for example, have documented that persons with pre-existing health conditions are more likely to become and remain unemployed (Bartley \& Owen, 1996; Bockerman \& Ilmakunnas, 2009; Bjorgulf Claussen, 1993; Salm, 2009). Browning, MollerDano, and Heinesen (2006) also reported that unemployment did not lead to hospitalization for stress-related diseases. While it has also been found that persons with health problems fare better in the long-run if they maintain or regain employment (Bartley, Sacker, \& Clarke, 2004; Huber, Lechner, \& Wunsch, 2010), this body of work suggests that pre-existing health may be a common cause of both unemployment and mortality.

Yet many studies continue to find an association between unemployment and mortality even after controlling for pre-existing health status. Whether these provide evidence of a causal link is still uncertain, and much of the debate over causation vs. spurious association has focused on health behavior variables. Unfortunately, the vast majority of individual-level studies of unemployment and health behaviors is cross-sectional and cannot be used to adjudicate between these two hypotheses. Furthermore, many of the macro-level studies of unemployment rates and aggregate health behavior measures cannot be used as they lack individual-level data on health behaviors, health outcomes, and employment status (Catalano \& Bellows, 2005). We therefore focus the review below on studies with individual-level data.

\section{The Latent Sickness Hypothesis}

Many researchers continue to argue that the unemployment-mortality association is spurious. These scholars argue that health selection into unemployment operates through health behavior variables rather than in a direct manner (i.e. the "latent sickness hypothesis") (Jusot et al., 2008). For example, if the health problems associated with high levels of drug, alcohol, and tobacco consumption manifest themselves only after the onset of unemployment, controlling for pre-existing health status would not effectively rule out health selection. In support of this view, studies have shown repeatedly that individuals with higher levels of smoking, drinking, and recreational drug use are more likely to become unemployed (Fergusson \& Boden, 2008; Hammer, 1997; Hoffmann, Dufur, \& Huang, 2007; Leino-Arjas, Liira, Mutanen, Malmivaara, \& Matikainen, 1999; Scott M. Montgomery, Bartley, Cook, \& Wadsworth, 1996; J. K. Morris, Cook, \& Shaper, 1992).

The latent sickness hypothesis is also supported, indirectly, by evidence that the income reduction associated with unemployment actually leads to positive changes in health behaviors (see Temple, Fillmore, Hartka, Johnstone, Leino, \& Motoyoshi, 1991). Reduced drinking and smoking have been found among the long-term unemployed (Fagan, Shavers, Lawrence, Gibson, \& Ponder, 2007; Hammer, 1992; Liira \& Leino-Arjas, 1999). Furthermore, improved physical activity levels have been found among the recently unemployed (Jurj, Wen, Gao, Matthews, Yang, Li et al., 2007; Matoba, Ishitake, \& Noguchi, 2003). Other studies have found no change in health behaviors, either positive or negative, resulting from unemployment (Gallo, Bradley, Siegel, \& Kasl, 2001; Goel, 2008; Iribarria, Ruiz, Pardo, \& San Martin, 2002; Peretti-Watel \& Constance, 2009; Rehm \& Gmel, 1999; Rodriguez \& Chandra, 2006; Virtanen, Vahtera, Broms, Sillanmaeki, Kivimaeki, \& Koskenvuo, 2008).

\section{The Coping Hypothesis}

Other researchers, however, continue to argue for causation, claiming that health behavior variables actually represent an important mediating mechanism through which unemployment is translated into mortality (i.e. the "coping hypothesis"). According to this view, individuals cope with unemployment stress by changing their consumption patterns in 
unhealthy ways (Hammarstrom, 1994; Laitinen, Ek, \& Sovio, 2002; Viinamaki, Niskanen, \& Koskela, 1997), particularly individuals with low socioeconomic status prior to the onset of unemployment (Kendzor, Cofta-Woerpel, Mazas, Li, Vidrine, Reitzel et al., 2008) and younger persons (S. L. Morrell, Taylor, \& Kerr, 1998). Individuals with low social status are thought to be particularly prone to negative coping because they feel that this type of stressrelief is all they have left (Peretti-Watel \& Constance, 2009).

A large body of work supports the coping hypothesis. First, multiple studies have found that alcohol consumption and binge drinking rise following unemployment (B. Claussen, 1999). This is especially true among men (Hammarstrom \& Janlert, 2003; Mossakowski, 2008; Virtanen et al., 2008), less educated people (Broman, Hamilton, Hoffmann, \& Mavaddat, 1995), young persons (U. Janlert \& Hammarstrom, 1992), and those involuntarily unemployed (Ettner, 1997). Second, unemployed persons, especially young men, are also more likely to increase their level of smoking (Barnes \& Smith, 2009; Bolton \& Rodriguez, 2009; Falba, Teng, Sindelar, \& Gallo, 2005; Hammarstrom \& Janlert, 1994, 2003; S. M. Montgomery, Cook, Bartley, \& Wadsworth, 1998; Reine, Novo, \& Hammarstrom, 2004). Unemployed smokers are less likely to attempt smoking cessation (Weden, Astone, \& Bishai, 2006) and are more likely to relapse from smoking cessation efforts (Falba et al., 2005). Finally, unemployed persons are more likely to increase their use of illicit drugs (Alegria, Vera, Shrout, Canino, Lai, Albizu et al., 2004; Hammer, 1992; Merline, O'Malley, Schulenberg, Bachman, \& Johnston, 2004) or begin using drugs (Crofts, Louie, Rosenthal, \& Jolley, 1996; Green, Doherty, Reisinger, Chilcoat, \& Ensminger, 2010).

Negative health consequences may also arise through the tendency of people to react to unemployment by reducing their personal spending. Research has shown that unemployed persons often substitute poorer quality diets for better ones. This may result in obesity (Laitinen, Power, Ek, Sovio, \& Jarvelin, 2002), or in unhealthy weight loss (Bolton \& Rodriguez, 2009). Some have even found that the threat of unemployment alone was enough to cause increased body mass index (BMI) (Ferrie, Shipley, Marmot, Stansfeld, \& Smith, 1998). Once unemployed, increased BMI creates a feedback loop, as those who are judged as overweight have difficulties in finding work (Johansson, Bockerman, Kiiskinen, \& Heliovaara, 2009; Paraponaris, Saliba, \& Ventelou, 2005) and increased BMI may therefore lead to permanent labor force withdrawal (Alavinia \& Burdorf, 2008).

The present study seeks to assess the impact of potential mediating, moderating, and confounding factors on the association between unemployment status and mortality. First, we evaluate the impact of pre-existing health status and health behaviors, variables that are central to the current debates in the literature. Using meta-analysis, we compare results from studies that controlled for health and/or health behaviors with other studies that did not. Second, in light of the literature on the potential moderating effects of national health care systems, we compare study results between countries with national health care systems and those without. Finally, we assess the potential moderating roles of gender, age, time, followup duration, and case/control group composition on the unemployment-mortality association. In each instance, we capitalize on cross-study variability to assess the impact of key factors. Becoming unemployed may also have a mediated effect on health due to the psychosocial stress of being forced into a lower social status (Fineman, 1979; Martikainen \& Valkonen, 1996), but this mediating factor is often assumed rather than empirically examined, and is therefore beyond the scope of the present study. 


\section{METHODS}

\section{Search strategy and coding procedures}

In June 2005, we conducted a search of electronic bibliographic databases to retrieve all publications combining the concepts of psychosocial stress, including unemployment, and all-cause mortality. We re-ran the electronic keyword searches in these databases in July 2008 and completed the search and coding stages in January 2009. We used 100 search clauses for Medline, 97 for EMBASE, 81 for CINAHL, and 20 for Web of Science. See Section 1 of Appendix for the full search algorithm used for Medline (information on the remaining search algorithms are available from authors upon request). We identified 1570 unique publications. Using these results as a base, we iteratively hand-searched the bibliographies of eligible publications; the lists of sources citing an eligible publication; and the sources identified as "similar to" an eligible publication. Hand-searching was ongoing for three and one-half years and was completed after 8 iterations (the full description of this iterative search protocol is documented and available from the authors upon request).

The electronic database searches were performed by a research librarian. Two authors (DR and ES) trained in systematic review coding procedures (Lipsey \& Wilson, 2001; Stock, 1994) determined publication eligibility and extracted the data from the articles, consulting a third author (JS) when required (see Section 2 of Appendix for additional details regarding coding procedures and variables for which data were sought). Any unpublished work encountered was considered for study inclusion. Although our search was done in English, we were able to locate and translate the relevant portions of 35 publications written in German, Danish, French, Spanish, Dutch, Polish, or Japanese. Figure 1 summarizes the number of publications considered at each step of the search process. The full database contains 262 publications examining the associations between various stressful events and all-cause mortality. To evaluate coding accuracy we randomly selected and recoded 40 of these publications (including 446 point estimates). Of the point estimates, $98.6 \%$ were free of coding errors.

The present analysis uses the subset of articles $(n=42)$ that reported the association between unemployment and all-cause mortality. Forty of these publications appeared in peerreviewed journals; 1 in a book chapter; and 1 in an unpublished dissertation. One publication was translated from Spanish in consultation with a native speaker; the remaining 41 publications were in English (Table 1).

\section{Statistical methods and inclusion criteria}

For the present analyses, a study was included if the outcome variable was all-cause mortality, unemployment was measured at the individual level (rather than at the neighborhood level), and a clear comparison was made between a group of people who experienced unemployment and another group who either did not experience unemployment at all or experienced it to a lesser degree. As shown in Table 1, most studies compared unemployed persons with employed persons, while a few compared unemployed persons with the general population. We examined whether this distinction affected the estimated association between unemployment and mortality.

Statistical methods varied from study to study, necessitating the conversion of odds ratios, rate ratios, standardized mortality ratios, relative risks, and hazard ratios (HRs) into a common metric (See Section 3 of Appendix). For 63 of the 235 measures of mortality risk, the death rate information required for conversion to a common metric was not reported. In these cases, the required death rate was estimated using multiple regression analysis (see Section 4 of Appendix). Sensitivity analyses were performed to examine the possible effect 
of including or excluding studies for which an estimated death rate was used in the conversion to a common metric.

As is standard practice, we used the standard errors reported in the publications to calculate the inverse variance weights (See Section 5 of Appendix). When not reported, standard errors were calculated using (1) confidence intervals, (2) $t$ statistics, (3) $\chi^{2}$ statistics, or (4) pvalues. When upper-limit p-values were the only estimate of statistical significance available (e.g. in cases where we knew only that the p-value lay somewhere between .01 and .05), the midpoint of the upper and lower limits was used to estimate the p-value. In 24 cases, no measure of statistical significance was reported and standard errors were estimated using multiple regression (See Section 4 of Appendix). An indicator variable was created so analyses could be conducted both with and without data points where the standard error was estimated.

Quality was assessed using the Newcastle-Ottawa scale for nonrandomized trials (Wells, Shea, O'Connell, Peterson, Welch, Losos et al., 2009). Two authors (DR and ES) also independently rated each publication, the average from these two ratings being used in the analysis.

$Q$-tests, $I^{2}$ tests, and examinations of the unexplained heterogeneity variance component were used to assess the presence and magnitude of heterogeneity in the data (HuedoMedina, Sanchez-Meca, \& Marin-Martinez, 2006). Q-test results from preliminary analyses revealed substantial heterogeneity across studies' effect sizes. In light of this all metaanalyses and meta-regression analyses were calculated by maximum likelihood using a random effects model and sensitivity analyses were conducted using the variables identified by the meta-regression models as significant sources of heterogeneity. Analysis was performed with statistical software (PASW, version 18.0) using matrix macros provided by Lipsey and Wilson (2001). The possibility of selection and publication bias was examined using a funnel plot of the log HRs against sample size. Funnel plot asymmetry was tested using Egger's test (Egger \& Davey-Smith, 1998). Due to the heterogeneity in the data, funnel plot asymmetry was also tested using weighted least squares regressions of the log HRs on the inverse of the sample size (Moreno, Sutton, Ades, Stanley, Abrams, Peters et al., 2009; Peters, Sutton, Jones, Abrams, \& Rushton, 2006).

Analyses performed include meta-analyses of subgroups, bivariate meta-regression analyses, and multivariate meta-regression analyses. The covariates used in the analyses were dictated by data availability. Variables such as race or ethnicity, which were used as grouping variables or included in interaction terms in only a small number of studies, could not be used in the analyses. Likewise, variables summarizing the prevalence of smoking or drinking, and other health behavior variables that would have been useful for additional analyses of confounding, were not reported and could therefore not be examined. The following independent variables were used in these analyses: (1) whether death rate was estimated (yes or no); (2) whether standard error was estimated (yes or no); (3) proportion of respondents who were male; (4) mean age of sample at baseline; (5) age of the study (i.e. years elapsed since the beginning of baseline), divided by 10; (6) time elapsed between the end of baseline and the beginning of follow-up; (7) maximum follow-up duration; (8) type of comparison group; (9) geographic region; (10) sample size, log transformed; (11) Newcastle-Ottawa Scale rating (range, 0-9); and (12) a series of variables indicating whether sex, age, socioeconomic status, and health were statistically controlled. 


\section{RESULTS}

Table 1 provides summary information on the 42 publications included in this study. This table is presented in lieu of the standard meta-analysis forest plot because of space limitations and the inherent difficulty in garnering data heterogeneity information from a plot that contains 235 point estimates and confidence intervals. The mean relative risk from each of the 42 publications, however, was included in Table 1 in the interest of providing information from which some heterogeneity observations might be made. The forest plot is available from the authors on request.

Table 2 provides descriptive statistics on the 235 mortality risk estimates included in this study. Data were obtained from 42 studies, published between 1984 and 2008, covering 15 countries (mostly in Europe and North America), and representing more than 20 million persons. The majority of persons analyzed were men, and almost all were of working age at baseline. The average follow-up duration across all studies was 9.02 years. Of the HRs analyzed, the mean 5-year impact factor was 5.59 and the mean number of citations received per year since publication was 2.68. The mean score on the Newcastle-Ottawa Scale was 7.76 .

Table 3 presents the results of a number of meta-analyses (See Table 4 for sample size information). All analyses were stratified by the level of statistical adjustment of the risk estimate. Persons who experienced unemployment were significantly more likely to die than the comparison group. The mean unadjusted HR was 2.08 (95\% confidence interval [CI], 1.77-2.43; $\mathrm{n}=40$ risk estimates); age-adjusted $\mathrm{HR}, 1.59(95 \% \mathrm{CI}, 1.42-1.77 ; \mathrm{n}=75)$; and HR adjusted for age and additional covariates, $1.63(95 \% \mathrm{CI}, 1.49-1.79 ; \mathrm{n}=120)$. These results show that unemployment is associated with a $63 \%$ higher risk of mortality in studies controlling for covariates. Table 3 also shows that the exclusion of data where either the death rate or the standard error had to be estimated does not alter the direction, magnitude, or level of statistical significance of the mean HRs.

\section{Subgroup Meta-analyses and Meta-regression Analyses}

As described at the end of the methods section, data on the prevalence of high BMI, smoking, drinking, drug use, or other health factors was not available for analysis. However, comparisons between the subset of our data where health was directly controlled ( $\mathrm{n}=45$

HRs) or where health-related behaviors were controlled ( $n=27 \mathrm{HRs})$ and the remaining data still provides results relevant to the debate between the coping hypothesis and the latent sickness hypothesis. Table 5 presents the results of the meta-regression analyses, which provide a multivariate test for differences between key sub-groups. Model 1 shows that there was no significant difference in HR magnitude between studies that controlled for any measure of health and the remaining studies $(\mathrm{p}=0.1236)$. Model 3 , however, shows that the mean HR was $24 \%$ lower for studies that controlled for one or more health behaviors, when compared to the remaining studies $(\mathrm{p}=.0159)$. These results suggest that health behaviors may confound the unemployment-mortality association to some degree. However, the results also indicate that pre-existing health behaviors and conditions do not account for $100 \%$ of the relationship between unemployment and mortality (see the discussion for more on this issue).

Previous studies suggested that gender is a key moderating variable for the unemploymentmortality association. Preliminary examinations of individual studies revealed qualitative differences between the magnitude of HRs for men and for women, suggesting that women and men be analyzed separately. Table 3 shows that unemployment was associated with an increased risk of death when HRs were adjusted for age and additional covariates. However, gender-specific analyses show that the magnitude of the association was greater for men 
(HR, 1.78; 95\% CI, 1.56-2.02; $\mathrm{n}=54 \mathrm{HRs}$ ) than for women (HR, 1.37; 95\% CI, 1.17-1.60; $\mathrm{n}$ $=36$ ). Model 3 of Table 5 confirms that the proportion of a sample that is male had a significant impact on the magnitude of the HR. The risk of death for men was $37 \%$ higher than that for women $(\mathrm{p}<.001)$.

Previous research has also suggested that age may moderate the association between unemployment and mortality. We therefore also conducted sub-group analyses based on average age at baseline. As shown in Table 3, unemployment was associated with a 73\% increased risk of all-cause mortality for people under the age of 40 years who were in their early careers (HR, $1.73 ; 95 \% \mathrm{CI}, 1.41-2.11 ; \mathrm{n}=29)$ and a $77 \%$ increased risk for those between the ages of 40 and 50 years who were in mid-career (HR, 1.77; 95\% CI, 1.59-1.98; $\mathrm{n}=70$ ). The association was substantially reduced for those between the ages of 50 and 65 years who were near the end of their working careers (HR, 1.25; 95\% CI, 1.03-1.52; $n=19$ ). The results of the meta-regression analysis (Model 3 of Table 5) show a significant effect for mean age (a 6\% decrease for each additional 10 years; $p=.0165$ ) confirm this finding, with HR magnitude being approximately equal between the youngest and the middle age group ( $p$ $=.4394)$ but $26 \%$ lower for the oldest age group $(\mathrm{p}=.0016)$.

While follow-up duration has not often been explored in the literature as a moderating factor, preliminary examinations of individual studies suggested that the association between unemployment and mortality may change as time passes. Sub-group analyses based on follow-up duration (Table 3) show that people who experienced unemployment had a 73\% higher risk of death during the first 5 years of follow-up (HR, 1.73; 95\% CI, 1.44-2.06; $\mathrm{n}=$ 30). The elevation of risk of death remained approximately the same when the follow-up duration averaged 5 to 10 years (HR, 1.76; 95\% CI, 1.55-2.00; $\mathrm{p}<.001 ; \mathrm{n}=47)$ but then decreased to a $42 \%$ elevation of risk in studies with a follow-up of more than 10 years (HR, $1.42 ; 95 \% \mathrm{CI}, 1.22-1.64 ; \mathrm{n}=43$ ). However, the meta-regression results indicate that there was no significant trend associated with follow-up duration $(\mathrm{p}=.3476)$.

Furthermore, the type of comparison group used may also have an effect on the magnitude of the mean HR. Preliminary comparisons of individual studies confirmed this, leading us to also examine sub-groups results based on the type of comparison group used. The mean HR was much higher when the comparison group was employed persons only (HR, 1.75; 95\% CI, 1.54-1.98; Table 3) than when the comparison group was the general population (HR, 1.24; 95\% CI, 1.01-1.51). The results of meta-regression analysis (Table 5) confirm this, showing that HRs were $32 \%$ lower when the general population was used as the comparison group ( $\mathrm{p}<.001$ ). Table 3 also shows that the risk of death was marginally lower when studies excluded persons not in the labor force (HR, 1.60; 95\% CI, 1.45-1.76) than when studies included a mixture of unemployed persons and those who were not in the labor force (HR, 1.73; 95\% CI, 1.46-2.04). However, the meta-regression analyses (Table 5) show that when unemployed persons were combined with persons not in the labor force the HR increased by $46 \%$ ( $\mathrm{p}<.001)$ once other study-level factors were controlled.

\section{Sensitivity Analysis}

The between-groups Cochrane's Q for the meta-analysis of all 235 HRs was statistically significant ( $\mathrm{p}=.0149)$ and the $I^{2}$ statistic was quite high $\left(I^{2}, 76.2 ; 95 \% \mathrm{CI}, 22.1-92.8\right)$, indicating that important moderating variables exist and supporting the decisions to use random effects models and conduct sub-group meta-analyses. As shown in Table 4, the $Q$ tests for these subgroup meta-analyses were statistically significant only for statisticallyunadjusted HRs. In all of the remaining subgroup analyses however, $Q$-tests and $I^{2}$ tests were non-significant, indicating that heterogeneity was adequately accounted for by the use of a random effects model. Since the discussion of the meta-analysis focused on HRs 
adjusted for age and additional covariates, the results discussed above are not an artifact of heterogeneity in the data.

To be conservative however, meta-regressions were used to examine other possible sources of heterogeneity in the data. The model fit statistics for Model 3 of Table $5\left(R^{2}, .3702\right.$; $\mathrm{p}<$. 001 for the Cochrane's $Q$ of the model) indicate that this model captured a very substantial portion of the heterogeneity in the data. Nevertheless, the unexplained heterogeneity variance component for this and the other models shown in Table 5 was highly significant (each $\mathrm{p}<.001$ ), confirming the need to use a random effects model for all analyses.

As reported earlier, health behaviors, sex, mean age, and the composition of the case and control groups moderate the mean HR. Model 3 of Table 5 shows that other significant moderators include the time elapsed between the end of baseline and the beginning of follow-up (a $6 \%$ increase in risk for each additional year; $\mathrm{p}=.0006$ ), whether the risk estimate was adjusted for age (a 16\% decrease when age was controlled; $\mathrm{p}=.0159$ ), and whether the risk estimate was adjusted for socioeconomic status (a 13\% decrease when SES was well-controlled; $\mathrm{p}=.0265$ ). While HRs from the United States and the Scandinavian nations are over-represented in the data, the results do not seem to be biased by this factor as there was no significant difference in HR magnitude between either region and the remaining nations $(\mathrm{p}=.7707$ and $\mathrm{p}=.9216$, respectively).

Of the 235 HRs, 93 were statistically-adjusted for age or had an age range smaller or equal to 35 years, did not use the general population as the control group, did not include persons not in the labor force in the case group, were from studies with less than a one year gap between the end of baseline and the beginning of follow-up, and were from studies in which men and women were analyzed separately. These 93 HRs were then grouped according to sex and age group, the resulting six sub-groups subjected separately to meta-analysis (see Table 6). The mean HR among women under the age of 40 was 1.73 (95\% CI, 1.41-2.11; n, $19)$, was 1.34 (95\% CI, $1.15-1.56 ; n, 14)$ when the mean age was 40 to 49.9 years, and was $0.94(95 \% \mathrm{CI}, 0.80-1.11 ; \mathrm{n}, 9)$ when the mean age was 50 years or above. The mean HR among men under the age of 40 was 1.95 (95\% CI, 1.69-2.26; n, 26), was 1.86 (95\% CI, n, 14) when mean age was 40 to 49.9 years, and was 1.17 (95\% CI, 1.00-1.36; n, 11) when the mean age was greater than or equal to 50 years. In all six meta-analyses, the $Q$-test was not significant and the $I^{2}$ statistic was not significantly different from zero, indicating homogeneity in the data. The high correspondence between these six more conservative meta-analyses and the full sample meta-analyses reported in Table 3 further confirm that heterogeneity in the sub-group data was not a major problem.

\section{DISCUSSION}

Our findings show that unemployment was associated with an increased relative risk of allcause mortality. We show that the risk of death was $63 \%$ higher among those who experienced unemployment than among those who did not, after adjustment for age and other covariates. Before proceeding to a more detailed discussion of the specific findings, however, some important limitations must be considered.

\section{Limitations}

There is also an unknown degree of nonreporting of nonsignificant findings (also known as the file-drawer effect) and selection bias that may affect the results (Berman \& Parker, 2002; Egger \& Davey-Smith, 1998). For example, some may suggest that the inclusion of studies based on census data is problematic because their analyses often rely on comparisons with the general population, as opposed to the employed population. While this is a valid point, we have tried to control for this by including the appropriate indicator variables in the 
analysis. To guard against other aspects of selection bias, we excluded no publications containing data on the association between unemployment and mortality. As with all metaanalyses however, some studies of the association between unemployment and mortality will have been missed. The funnel plot of the log HRs against sample size appears asymmetric around the mean HR, suggesting significant selection bias (Figure 2). The results of Egger's test indicated significant funnel plot asymmetry $(\mathrm{p}<.001)$. However, recent simulation studies indicate that heterogeneity in the data (such as is the case here) produces misleading Egger's test results (Moreno et al., 2009; Peters et al., 2006; Terrin, Schmid, Lau, \& Olkin, 2003). Using Peters' test (Moreno et al., 2009; Peters et al., 2006), we regressed the $\log$ HRs on the inverse of the sample size. The results of this second test indicated non-significant levels of funnel plot asymmetry after data heterogeneity had been taken into account $(\mathrm{p}=.993)$. Given the discrepancy in the results of the two tests, however, caution is warranted in the interpretation of the results.

Another limitation stems from the reliance on studies with observational designs, which limit the ways in which one can account for potential confounders. None of the studies of unemployment were randomized clinical trials, as unemployment is not a "treatment" one induces. In the worst case scenario, the use of an observational design creates the risk that one or more highly important confounding factors are not accounted for and the results of the study are biased (Egger, Schneider, \& Davey-Smith, 1998). Even when important factors are controlled, differences in the method of control between studies have the potential to affect the results of a meta-analysis. For example, Model 3 in Table 5 shows that the method for controlling for socioeconomic status affects the magnitude of the HR. While the HR associated with unemployment is elevated across all levels of control for SES, the mean HR was $13 \%$ lower among the subset which measured SES using two or more factors. There is a danger of systematic bias in our results due to our reliance on studies with observational designs and due to the different methods used to control for confounders in the studies we examined. However, this danger is reduced by our efforts to account for the mediating, moderating, and confounding factors that have thus far been investigated in the literature.

\section{Discussion}

Three findings from our study support the idea that the pathway between unemployment and mortality is not completely spurious, and could be consistent with a causal association. First, unemployment remains associated with an increased risk of death even after the exclusion of individuals who were not in the labor force. This supports Moser et al.'s (1987) finding that elevated risk levels among the unemployed were not simply an artifact of misclassification. Second, the lack of significant difference between the subset of our data where health was directly controlled $(\mathrm{n}=45 \mathrm{HRs})$ and the remaining data $(\mathrm{p}=.1236)$ suggests that pre-existing health problems were not, in a broad sense, the common cause of both unemployment and mortality. These findings are consistent with those of Lunden et al. (2010), who reported that a substantial portion of the association between unemployment and mortality remained even after accounting for possible confounding factors. However, our regressions indicated that the $27 \mathrm{HRs}$ that controlled for health behaviors were $24 \%$ lower than the remaining HRs $(\mathrm{p}=.0159)$. This latter result provides limited support for the latent sickness hypothesis. Health-related behaviors existing at baseline account for a portion of the unemploymentmortality association and are clearly important to include in future studies. However, the coping hypothesis provides a better overall explanation as the lack of large differences in HR magnitude suggests that the post-unemployment pathway exerts a stronger effect on mortality outcomes. The method available to us for the testing of these competing hypotheses, while suggestive of the overarching patterns, cannot provide definitive evaluations of these hypotheses. 
The results of this systematic review confirm our early expectations that the estimated adverse association between unemployment and mortality would not be uniform across all subgroups and studies. Meaningful differences were observed by age group, gender, followup duration, time period, geographic region, and case and control group composition.

First, mean HRs were higher for those in their early and middle careers (an increased risk of $73 \%$ and $77 \%$, respectively) but lower for persons in their late careers (only a $25 \%$ increase in risk), a finding consistent with those of earlier reports (Iversen, Andersen, Andersen, Christoffersen, \& Keiding, 1987; Moser, Fox, \& Jones, 1984; Sorlie \& Rogot, 1990). This pattern may be the result of a smaller net increase in stress among older workers, who often hold jobs with above average stress levels and who may have already been contemplating retirement (Brenner \& Levi, 1987). The pattern may also result from health selection into retirement among older workers (Disney, Emmerson, \& Wakefield, 2006), a process that leads to the overrepresentation of healthier older persons in the workforce. Some caution must be exercised when interpreting this finding. When the underlying death rates are very high in both the case and control groups (as is the case at older ages), ratio statistics such as the HR lack statistical power to detect group differences. However, this is not likely a problem in the present study because we focus on the working-age population. The death rates remain low enough to enable ratio-type measures such as HRs to detect differences in death rates between the employed and unemployed.

Second, this study confirms that the magnitude of the association between unemployment and mortality is higher for men than for women (an increased risk of $78 \%$ vs. 37\%). There are two possible explanations for this finding. First, the labor force participation rate for women is considerably lower than for men in most nations. Being engaged in unpaid labor at home or employed as part-time or on a temporary basis may provide less health protection than full-time work. The data can be used to partially evaluate this first explanation. The difference between men's and women's labor force participation rates is particularly low in the Scandinavian nations, and if this first explanation is valid one would expect to see a correspondingly smaller difference between men's and women's relative mortality risk. To test this we included an interaction term between gender and Scandinavian region in a separate meta-regression (not shown in tables, but using the same covariates as Model 2 in Table 5). The lack of significance for the interaction term $(\mathrm{p}=.8156)$ suggests that absolute differences in the labor force participation rate between men and women do not account for differences in the relative mortality risk. A second explanation for the gender gap in relative mortality risks may be that employment status remains more central to men's identities than to women's despite the continuing upward trend in women's participation in the formal labor market. This explanation cannot be evaluated with our data.

Third, the association between unemployment and mortality is significant in both the short and long term. While the meta-analysis results showed a decrease in the mean risk of mortality in those studies where the follow-up period exceeded 10 years (the risk dropped from $76 \%$ to $42 \%$ ), this trend was not significant in the final meta-regression model ( $\mathrm{p}=$. 3476). This finding must be approached conservatively as it may result from the fact that many of the studies included in the meta-analysis were cross-sectional. In cross-sectional studies the employment status reported at baseline tends to become less and less accurate as time passes. In other words, group differences may become obscured over time because some of those who initially reported being unemployed later found work and some who were employed at baseline (and served as the comparison group) later lost their jobs. The constancy of the mean relative risk over time, however, does lend some support to the hypothesis and previous findings that both the stress and the negative lifestyle effects associated with the onset of unemployment tend to persist even after a person has regained a job (Bolton \& Rodriguez, 2009; Cohen, Kemeny, Zegans, Johnson, Kearney, \& Stites, 2007; 
Janicki-Deverts, Cohen, Matthews, \& Cullen, 2008; Khan, Murray, \& Barnes, 2002; S. M. Montgomery et al., 1998; Wadsworth, Montgomery, \& Bartley, 1999).

Fourth, the results of the meta-regression analyses show no significant changes in the magnitude of the unemployment-mortality association over the last four decades, as shown by the lack of a significant association between the age of a study and the magnitude of the HR (Model 2 of Table 5; $\mathrm{p}=.6972$ ). Despite dramatic changes in the composition of the workforce and in work environments over this period (such as women's increased labormarket participation, changing government unemployment policies, and the general trend towards more part-time and temporary jobs), the association between unemployment and mortality remained unchanged.

Fifth, the results of the meta-regressions suggest that differences between national welfare and health-care systems may not translate into differences in the magnitude of the unemployment-mortality association. Ideally, this question would be tested using a direct measure of national health system scope. While this data was not available for our analyses, the geographic region variables can be used to partially assess the hypothesis. Among the nations represented in this study (see Table 2 for a complete list), only the United States lacks some form of universal health coverage. Furthermore, unemployment benefits in the United States tend to be less generous than in most of the other nations examined. In contrast, public health care coverage is most comprehensive in the Scandinavian nations. If the degree of coverage provided by national welfare and health-care systems was related to the unemployment-mortality association, one would expect to see significant differences in HR magnitude between the U.S. and the Scandinavian nations. The lack of a significant difference between the mean HR for the U.S. $(p=.7707)$, Scandinavia $(p=.9216)$, and the remaining nations suggests that these national-level policy differences may not have much of an effect on the rate of mortality following unemployment. This result should be treated conservatively and should not be extrapolated to populations in developing countries, as almost all the data came from studies of the developed world.

Finally, the composition of both the cases and controls was important. When comparing unemployed persons with the general population, the effect is much smaller than when comparing unemployed persons with employed persons (the risk decreases from $75 \%$ to 24\%). This is to be expected because the general population, while primarily consisting of employed persons, also includes some unemployed persons and individuals who are not in the labor force (e.g. early retirees, the disabled, homemakers, and students). Furthermore, the mean risk of death increases (from 60\% to 73\%) when those who are not in the labor force are mixed with the unemployed. This confounds the stress of unemployment with health status and other factors that may influence the magnitude of the association. These findings suggest that future studies of the unemployment-mortality association must strive to include only unemployed persons as cases and only employed persons as controls. The quality of study design is critical for assessing the risk of death among unemployed persons because this risk tends to be understated if cases or controls are not both precisely specified.

\section{Conclusion}

This study shows that unemployment was associated with a substantially increased risk of death among broad segments of the population. Future research should continue to focus on possible mediating, moderating, and confounding factors and on whether this risk is modifiable, either at the health system level or the individual level. Until more is known about the mechanisms by which this association occurs, more proactive primary prevention screening and interventions among the unemployed are needed. Due caution is warranted, however, as Dorling (2009) suggests that some interventions, such as low-wage work programs, appear to exacerbate the hazard of dying due to unemployment. However, studies 
suggest that cardiovascular screening programs among the unemployed, interventions aimed at increasing unemployed persons' awareness of behavioral risk factors (Hanewinkel, Wewel, Stephan, Isensee, \& Wiborg, 2006), and stress-management programs (aimed at preventing risk-taking behavior that leads to the observed increase in injury rates among the unemployed) may be particularly beneficial. Studies such as the current one are particularly important in the current economic climate, with many national unemployment rates exceeding $10 \%$ and expected to remain elevated for some time. Much work remains to be done using more detailed specifications of unemployment for which systematic data could not be found. Studies should be conducted in developing nations, where welfare and health care systems are much less developed and unemployment may result in more direct threats to a person's health. Future studies should also collect data on unemployment duration, informal labor market participation, sources of support, and other possible mediators beyond those discussed in this paper.

\section{Acknowledgments}

The authors are grateful for the support provided by grant HL-76857 from the National Institutes of Health. The funding source had no involvement in the collection, analysis and interpretation of the data, in the writing of the report, and in the decision to submit the paper for publication.

\section{Appendix}

\section{Section 1: Full search algorithms for Medline}

1. exp stress, psychological/mo

2. exp Stress, Psychological/

3. exp mortality/

4. mo.fs.

5. (death\$ or mortalit\$ or fatal\$).tw.

6. or $/ 3-5$

7. 2 and 6

8. 1 or 7

9. stress\$.tw.

10. exp caregivers/

11. caregiv $\$ . t w$.

12. (care giver\$ or care giving).tw.

13. exp family/

14. exp siblings/

15. exp divorce/

16. exp marriage/

17. (marital adj (strife or discord)).tw.

18. widow\$.tw.

19. (marriage or married).tw.

20. divorce $\$$.tw. 
21. famil\$.tw.

22. (son or sons).tw.

23. daughter\$.tw.

24. (spous\$ or partner\$ or husband $\$$ or wife or wives).tw.

25. (mother\$ or father $\$$ or sibling $\$$ or sister $\$$ or brother $\$$ ).tw.

26. exp dissent/ and disputes.mp. [mp=title, original title, abstract, name of substance word, subject heading word]

27. exp domestic violence/

28. domestic violence.tw.

29. ( (child $\$$ or partner $\$$ or spous $\$$ or elder $\$$ or wife or wives) adj5 (violen $\$$ or abuse $\$$ or

30. beat $\$$ or cruelty or assault $\$$ or batter $\$))$.tw.

31. ((mental\$ or physical\$ or verbal or sexual\$) adj2 (violen $\$$ or abuse $\$$ or cruelty)).tw.

32. exp PEDOPHILIA/

33. (pedophil\$ or paedophil\$).tw.

34. exp social class/

35. exp socioeconomic factors/

36. (socioeconomic\$ or socio economic\$).tw.

37. ((financ\$ or money or economic) adj (stress $\$$ or problem $\$$ or hardship $\$$ or burden \$)).tw.

38. exp poverty/

39. (poverty or poor or depriv\$).tw.

40. exp residence characteristics/

41. ((neighbo?rhood or resident\$) adj (characteristic\$ or factor\$)).tw.

42. (crowd $\$$ or overcrowd $\$)$.tw.

43. exp prejudice/

44. (prejudic $\$$ or racis $\$$ or discriminat $\$$ ).tw.

45. exp social isolation/

46. exp social support/

47. (social adj (isolat $\$$ or support $\$$ or connect $\$$ or depriv $\$$ or function $\$$ or influen $\$$ or interact $\$$ or relationship $\$$ or separat $\$$ or ties)).tw.

48. exp friends/

49. (acquaintance $\$$ or companion $\$$ or friend $\$$ ).tw.

50. neighbo?r\$.tw.

51. exp interpersonal relations/

52. (social adj network\$).tw.

53. exp social behavior/ 
54. (social\$ adj activ\$).tw.

55. exp work/

56. exp employment

57. exp job satisfaction/

58. exp work schedule/

59. exp occupational disease/

60. exp occupational health/

61. exp workplace/

62. (job or jobs).ti,ab.

63. employ\$.ti,ab.

64. unemploy $\$ . t i, a b$.

65. (shiftwork $\$$ or (work adj 2 shift $\$$ )).ti,ab.

66. karasek $\$$.ti,ab.

67. overwork\$.ti,ab.

68. ((job or work or employ $\$$ or occupation $\$$ ) adj (satisf $\$$ or condition $\$$ or discontent or stress\$)).ti,ab.

69. $\exp$ ACCULTURATION/

70. acculturat\$.ti,ab.

71. (migrant $\$$ or immigrant $\$$ or guest work $\$$ ).ti,ab.

72. exp Life Change Events/

73. ((trauma $\$$ or life) adj (change or event $\$$ or stress $\$)) . t i, a b$.

74. exp natural disasters/

75. (natural disaster $\$$ or earthquake $\$$ or hurricane $\$$ or volcan $\$$ or typhoon $\$$ or tsunami $\$$ or avalanche\$ or fire $\$$ or flood\$).ti,ab.

76. $\exp$ FIRES/

77. exp STRESS DISORDERS, POSTTRAUMATIC/ or exp OXIDATIVE STRESS/ or exp ECHOCARDIOGRAPHY, STRESS/ or exp HEAT STRESS DISORDERS/ or exp DENTAL STRESS ANALYSIS/ or exp STRESS, MECHANICAL/ or exp STRESS FIBERS/ or exp URINARY INCONTINENCE, STRESS/ or exp

FRACTURES, STRESS/ or stress disorders, traumatic, acute/ or exp exercise test/

78. ((stress or exercise) adj test\$).sh,tw.

79. exp Accidents, Occupational/

80. (occupation $\$$ adj (hazard $\$$ or accident $\$$ )).tw.

81. or $/ 76-79$

82. 2 or 9

83. or $/ 10-75$

84. or $/ 76-79$ 
85. 82 not 83

86. and $/ 6,81,84$

87. 8 or 85

88. exp Cohort Studies/

89. Controlled Clinical Trials/

90. controlled clinical trial.pt.

91. ((incidence or concurrent) adj (study or studies)).tw.

92. comparative study.sh.

93. evaluation studies.sh.

94. follow-up studies.sh.

95. prospective studies.sh.

96. control\$.tw.

97. prospectiv\$.tw.

98. volunteer\$.tw.

99. or/87-97

100.86 and 98

101.limit 99 to humans

\section{Section 2: Coding procedures and variables for which data were sought}

As already mentioned in the main text, two authors (DR and ES) trained in systematic review coding procedures determined publication eligibility and extracted the data from the articles. Prior to coding, both authors jointly reviewed the titles and abstracts of potential publications to determine whether a given work warranted a full examination for coding purposes. Each of these publications was read independently, with each author forming an opinion on final publication eligibility, assigning a tentative subjective quality rating, and highlighting the data to be coded (see below). The two authors then met in conference to discuss each publication. Data was entered into a spreadsheet only after agreement had been reached on final publication eligibility, the number of relative risk estimates available for extraction, the values to be assigned for the study design variables (e.g. age range, baseline date) corresponding to each relative risk, and consensus had been established with respect to the final subjective quality rating. In some cases, the data entry involved calculating relative risk estimates from raw death rates or from raw count data. For publications reporting multiple analyses of a single sample, data was sought from a statistically-unadjusted model, a model adjusted for age alone, and from the most statistically-adjusted multivariate model. Data was entered basic spreadsheets (the data spreadsheet being later imported into SPSS for analysis). The variables we sought to obtain from publications were:

1) Author names; 2) author genders; 3) publication date; 4) publication title; 5) place of publication; 6) characteristics of high stress group (e.g. unemployed); 7) characteristics of low stress group (e.g. employed); 8) characteristics shared by both high and low stress groups; 9) percent of the sample that was male; 10) minimum age; 11) maximum age; 12) mean age; 13) ethnicity; name of data source used; 14) geographic location of study sample; 15) baseline start date (day, month, year); 16) baseline end date (day, month, year); 17) follow-up end date (day month, year); 18) maximum follow-up duration; 19) average 
follow-up duration; 20) information on timing of stress relative to baseline start date; 21) information on the structure of the follow-up period (e.g. were there any gaps between the end of baseline and the beginning of follow-up?); 22) statistical technique used;23) total number of persons analyzed in the publication; 24) total number of persons analyzed for the specific effect size; 25) number of persons in the high stress group; 26) number of deaths in the high stress group; 27) number of persons in the low stress group; 28) number of deaths in the low stress group; 29) death rate in the high stress group; 30) death rate in the low stress group; 31) effect size; 32) confidence interval; 33) standard error; 34) t-statistic; 35) Chi-square statistic; 36) minimum value for $\mathrm{p}$-value; 37) maximum value for $\mathrm{p}$-value; 38) full list of control variables used; 39) date of data extraction; 40) subjective quality rating; 41) number of citations received by publication according to Web of Science; 42) number of citations received according to Google Scholar; 43) 5-year impact factor for place of publication.

\section{Section 3: Additional information on the conversion of odds ratios and relative risks to hazard ratios}

All non-hazard-ratio point estimates were converted to hazard ratios (the most frequently reported type) using one or both of the following equations (Zhang \& Yu, 1998):

$\mathrm{RR}=\frac{\mathrm{OR}}{(1-\mathrm{r})+(\mathrm{r} * \mathrm{OR})}$ and $\mathrm{HR}=\frac{\ln (1-\mathrm{RR} * \mathrm{r})}{\ln (1-\mathrm{r})}$, where $\mathrm{RR}$ is the relative risk, $\mathrm{OR}$ is the odds ratio, $\mathrm{HR}$ is the hazard ratio, and $r$ is the death rate for the reference (i.e. employed) group.

\section{Section 4: Additional information on the estimation of death rates and standard errors}

Significant predictors of the death rate were follow-up duration, mean age at baseline, sample size (log transformed), an indicator for whether the study statistically controlled for gender, the subjective quality assessment score assigned by the coders, the proportion of the sample that was male, and an indicator for whether the study statistically controlled for age. Multiple $R=.797$. As mortality is the outcome variable in the included studies, it needs to be made explicit that it was the death rate (used to convert different measures of relative risk to a common metric) that was estimated, not the mortality risk estimate itself.

Significant predictors of the standard error were sample size (log transformed), mean age at baseline, follow-up duration, the magnitude of the hazard ratio, and publication date. Multiple $R=.721$.

\section{Section 5: Additional information on method for adjusting inverse variance weights}

Many meta-analysts prefer to use only the most general point estimates reported in a given publication. While this strategy makes it easier to maintain independence between point estimates and makes the calculations of the inverse variance weights straight-forward, it also results in a substantial loss of information. We sought instead to maximize the number of point estimates analyzed, capturing variability both between and within each publication rather than just the former. For example, when a publication (see hypothetical Study X in Table A1) reported mortality risks by gender sub-groups alone the data requires no adjustment. Likewise, when a study reported mortality risks by age group alone (see hypothetical Study Y) the data also requires no adjustment. However, when a publication first reports mortality risks by gender and then again by age (see hypothetical Study Z) this 
creates a violation of independence because each person is represented twice. To correct for this double-counting, each of the variance weights was adjusted to half of its original value, thus preserving information on the gender and age variables while effectively counting each subject only once.

\section{References}

Ahs AMH, Westerling R. Mortality in Relation to Employment Status during Different Levels of Unemployment. Scandinavian Journal of Public Health. 2006; 34:159-167. [PubMed: 16581708]

Alavinia SM, Burdorf A. Unemployment and Retirement and Ill-Health: A Cross-Sectional Analysis Across European Countries. International Archives of Occupational and Environmental Health. 2008; 82(1):39-45. [PubMed: 18264715]

Alegria M, Vera M, Shrout P, Canino G, Lai SH, Albizu C, et al. Understanding Hard-Core Drug Use Among Puerto Rican Women in High-Risk Neighborhoods. Addictive Behaviors. 2004; 29(4):643664. [PubMed: 15135547]

Anson J. The Migrant Mortality Advantage: A 70 Month Follow-up of the Brussels Population. European Journal of Population-Revue Europeenne De Demographie. 2004; 20(3):191-218.

Bambra C, Eikemo T. Welfare State Regimes, Unemployment and Health: A Comparative Study of the Relationship Between Unemployment and Self-Reported Health in 23 European Countries. Journal of Epidemiology and Community Health. 2009; 63(2):92-98. [PubMed: 18930981]

Barnes MG, Smith TG. Tobacco Use as Response to Economic Insecurity: Evidence from the National Longitudinal Survey of Youth. B E Journal of Economic Analysis \& Policy. 2009; 9(1) Article Number 47.

Bartley M, Owen C. Relation Between Socioeconomic Status, Employment, and Health During Economic Change, 1973-93. British Medical Journal. 1996; 313(7055):445-449. [PubMed: 8776309]

Bartley M, Sacker A, Clarke P. Employment Status, Employment Conditions, and Limiting Illness: Prospective Evidence from the British Household Panel Survey 1991-2001. Journal of Epidemiology and Community Health. 2004; 58(6):501-506. [PubMed: 15143119]

Berman NG, Parker RA. Meta-Analysis: Neither Quick nor Easy. BMC Medical Research Methodology. 2002; 2:10-18. [PubMed: 12171604]

Blakely T, Atkinson J, Ivory V, Collings S, Wilton J, Howden-Chapman P. No Association of Neighbourhood Volunteerism with Mortality in New Zealand: A National Multilevel Cohort Study. International Journal of Epidemiology. 2006; 35(4):981-989. [PubMed: 16931531]

Bockerman P, Ilmakunnas P. Unemployment and Self-assessed Health: Evidence from Panel Data. Health Economics. 2009; 18(2):161-179. [PubMed: 18536002]

Bolton KL, Rodriguez E. Smoking, Drinking and Body Weight after Re-employment: Does Unemployment Experience and Compensation Make a Difference? BMC Public Health. 2009 Article Number 77.

Brenner S-O, Levi L. Long-term Unemployment Among Women in Sweden. Social Science and Medicine. 1987; 25(2):153-161. [PubMed: 3660005]

Broman CL, Hamilton VL, Hoffmann WS, Mavaddat R. Race, Gender, and the Response to Stress: Autoworkers' Vulnerability to Long-term Unemployment. American Journal of Community Psychology. 1995; 23(6):813-842. [PubMed: 8638552]

Browning M, Moller Dano A, Heinesen E. Job Displacement and Stress Related Health Outcomes. Health Economics. 2006; 15(10):1061-1075. [PubMed: 16518795]

Catalano R, Bellows B. If Economic Expansion Threatens Public Health, Should Epidemiologists Recommend Recession? International Journal of Epidemiology. 2005; 34:1212-1213. [PubMed: 16051616]

Claussen B. A Clinical Follow Up of Unemployed I: Lifestyle, Diagnoses, Treatment and Reemployment. Scandinavian Journal of Primary Health Care. 1993; 11(3):211-218. [PubMed: 8272655]

Claussen B. Alcohol Disorders and Re-employment in a 5-Year Follow-up of Long-term Unemployed. Addiction. 1999; 94(1):133-138. [PubMed: 10665105] 
Cohen F, Kemeny ME, Zegans LS, Johnson P, Kearney KA, Stites DP. Immune Function Declines with Unemployment and Recovers After Stressor Termination. Psychosomatic Medicine. 2007; 69(3):225-234. [PubMed: 17401058]

Costa G, Segnan N. Unemployment and Mortality. British Medical Journal. 1987; 294(June):1550_ 1551. [PubMed: 3111631]

Crofts N, Louie R, Rosenthal D, Jolley D. The First Hit: Circumstances Surrounding Initiation Into Injecting. Addiction. 1996; 91(8):1187-1196. [PubMed: 8828246]

Disney R, Emmerson C, Wakefield M. Ill Health and Retirement in Britain: A Panel Data-based Analysis. journal of Health Economics. 2006; 25(4):621-649. [PubMed: 16678924]

Dorling D. Unemployment and Health: Health Benefits Vary According to the Method of Reducing Unemployment. British Medical Journal. 2009; 338 Article Number b829.

Egger M, Davey-Smith G. Meta-analysis: Bias in Location and Selection of Studies. British Medical Journal. 1998; 316(7124):61-66. [PubMed: 9451274]

Egger M, Schneider M, Davey-Smith G. Meta-analysis Spurious Precision? Meta-analysis of Observational Studies. British Medical Journal. 1998; 316(January):140. [PubMed: 9462324]

Ettner SL. Measuring the Human Cost of a Weak Economy: Does Unemployment Lead to Alcohol Abuse? Social Science and Medicine. 1997; 44(2):251-260. [PubMed: 9015877]

Fagan P, Shavers V, Lawrence D, Gibson JT, Ponder P. Cigarette Smoking and Quitting Behaviors Among Unemployed Adults in the United States. Nicotine \& Tobacco Research. 2007; 9(2):241248. [PubMed: 17365755]

Falba T, Teng HM, Sindelar JL, Gallo WT. The Effect of Involuntary Job Loss on Smoking Intensity and Relapse. Addiction. 2005; 100(9):1330-1339. [PubMed: 16128722]

Farmer IP, Meyer PS, Ramsey DJ, Goff DC, Wear ML, Labarthe DR, et al. Higher Levels of Social Support Predict Greater Survival Following Acute Myocardial Infarction: The Corpus Christi Heart Project. Behavioral Medicine. 1996; 22(2):59-66. [PubMed: 8879457]

Fergusson DM, Boden JM. Cannabis Use and Later Life Outcomes. Addiction. 2008; 103(6):969-976. [PubMed: 18482420]

Ferrie JE, Shipley MJ, Marmot MG, Stansfeld SA, Smith GD. An Uncertain Future: The Health Effects of Threats to Employment Security in White-Collar Men and Women. American Journal of Public Health. 1998; 88(7):1030-1036. [PubMed: 9663149]

Fineman S. A Psychosocial Model of Stress and Its Application to Managerial Unemployment. Human Relations. 1979; 32(4):323-345.

Gallo WT, Bradley EH, Siegel M, Kasl SV. The Impact of Involuntary Job Loss on Subsequent Alcohol Consumption by Older Workers: Findings from the Health and Retirement Survey. Journals of Gerontology Series B: Psychological Sciences and Social Sciences. 2001; 56(1):S3S9.

Gardner J, Oswald A. How is Mortality Affected by Money, Marriage, and Stress? Journal of Health Economics. 2004; 23(6):1181-1207. [PubMed: 15556242]

Gerdtham U, Johannesson M. Business Cycles and Mortality: Results from Swedish Microdata. Social Science and Medicine. 2005; 60(1):205-218. [PubMed: 15482879]

Gerdtham U, Ruhm CJ. Deaths Rise in Good Economic Times: Evidence from the OECD. Economics and Human Biology. 2006; 4(3):298-316. [PubMed: 16713407]

Gerdtham UG, Johannesson M. A Note on the Effect of Unemployment on Mortality. journal of Health Economics. 2003; 22(3):505-518. [PubMed: 12683964]

Goel RK. Unemployment, Insurance, and Smoking. Applied Economics. 2008; 40(20):2593-2599.

Gognalons-Nicolet M, Derriennic F, Monfort C, Cassou B. Social Prognostic Factors of Mortality in a Random Cohort of Geneva Subjects Followed Up for a Period of 12 Years. Journal of Epidemiology and Community Health. 1999; 53(3):138-143. [PubMed: 10396489]

Green KM, Doherty EE, Reisinger HS, Chilcoat HD, Ensminger M. Social Integration in Young Adulthood and the Subsequent Onset of Substance Abuse and Disorders Among a Community Population of Urban African Americans. Addiction. 2010; 105(3):484-493. [PubMed: 20402992]

Hammarstrom A. Health Consequences of Youth Unemployment: Review from a Gender Perspective. Social Science and Medicine. 1994; 38(5):699-709. [PubMed: 8171348] 
Hammarstrom A, Janlert U. Unemployment and Change of Tobacco Habits: A Study of Young-People from 16 to 21 Years of Age. Addiction. 1994; 89(12):1691-1696. [PubMed: 7866253]

Hammarstrom A, Janlert U. Unemployment - An Important Predictor for Future Smoking: A 14-year Follow-up Study of School Leavers. Scandinavian Journal of Public Health. 2003; 31(3):229-232. [PubMed: 12850978]

Hammer T. Unemployment and Use of Drug and Alcohol and Young People: A Longitudinal Study in the General Population. British Journal of Addiction. 1992; 87(11):1571-1581. [PubMed: 1458036]

Hammer T. History Dependence in Youth Unemployment. European Sociological Review. 1997; 13(1):17-33.

Hanewinkel R, Wewel M, Stephan C, Isensee B, Wiborg G. Motivational Interviewing of Unemployed: Acceptance and Effects of Counselling to Improve Health-Related Behaviour. Gesundheitswesen. 2006; 68(4):240-248. [PubMed: 16705560]

Hanisch KA. Job Loss and Unemployment Research from 1994-1998: A Review and Recommendations for Research and Intervention. Journal of Vocational Behavior. 1999; 55(2): $188-220$.

Helweg-Larsen M, Kjoller M, Thoning H. Do Age and Social Relations Moderate the Relationship between Self-rated Health and Mortality among Adult Danes? Social Science \& Medicine. 2003; 57:1237-1247. [PubMed: 12899907]

Herring AA, Bonilla-Carrión RE, Borland RM, Hill KH. Differential Mortality Patterns Between Nicaraguan Immigrants and Native-born Residents of Costa Rica. Journal of Immigrant and Minority Health. 2008 Online First(February 9).

Hirokawa K, Tsutusmi A, Kayaba K. Impacts of Educational Level and Employment Status on Mortality for Japanese Women and Men: The Jichi Medical School Cohort Study. European Journal of Epidemiology. 2006; 21:641-651. [PubMed: 17048083]

Hoffmann JP, Dufur M, Huang L. Drug Use and Job Quits: A Longitudinal Analysis. Journal of Drug Issues. 2007; 37(3):569-596.

Huber M, Lechner M, Wunsch C. Does Leaving Welfare Improve Health? Evidence for Germany. Health Economics. 2010 Published online in advance of print edition.

Huedo-Medina TB, Sanchez-Meca J, Marin-Martinez F. Assessing Heterogeneity in Meta-analysis: Q Statistic or I ${ }^{2}$ Index? Psychological Methods. 2006; 11(2):193-206. [PubMed: 16784338]

Iribarria JAD, Ruiz MA, Pardo A, San Martin R. The Effects of Unemployment Duration. Psicothema. 2002; 14(2):440-443.

Iversen L, Andersen O, Andersen PK, Christoffersen K, Keiding N. Unemployment and Mortality in Denmark, 1970-80. British Medical Journal. 1987; 295:879-884. [PubMed: 3119084]

Janicki-Deverts D, Cohen S, Matthews KA, Cullen MR. History of Unemployment Predicts Future Elevations in C-Reactive Protein among Male Participants in the Coronary Artery Risk Development in Young Adults (CARDIA) Study. Annals of Behavioral Medicine. 2008; 36(2): 176-185. [PubMed: 18784972]

Janlert U. Unemployment as a Disease and Diseases of the Unemployed. Scandinavian Journal of Work and Environmental Health. 1997; 23(Supplement 3):79-83.

Janlert U, Hammarstrom A. Alcohol-Consumption Among Unemployed Youths: Results from a Prospective Study. British Journal of Addiction. 1992; 87(5):703-714. [PubMed: 1591521]

Jantti, M.; Martikainen, P.; Valkonen, T. When the Welfare State Works: Unemployment and Mortality in Finland. In: Cornia, A.; Paniccia, R., editors. The Mortality Crisis in Transitional Economies. Oxford University Press; Oxford: 2000. p. 351-369.

Jenkinson CM, Madeley RJ, Mitchell JRA, Turner ID. The Influence of Psychosocial Factors on Survival after Myocardial Infarction. Public Health. 1993; 107(5):305-317. [PubMed: 8248465]

Jin RL, Shah CP, Svoboda TJ. The Impact of Unemployment on Health: A Review of the Evidence. Canadian Medical Association Journal. 1995; 153(5):529-540. [PubMed: 7641151]

Johansson E, Bockerman P, Kiiskinen U, Heliovaara M. Obesity and Labour Market Success in Finland: The Difference Between Having a High BMI and Being Fat. Economics and Human Biology. 2009; 7(1):36-45. [PubMed: 19249259] 
Johnson JE, Finney JW, Moos RH. Predictors of 5-Year Mortality Following Inpatient/Residential Group Treatment for Substance Use Disorders. Addictive Behaviors. 2005; 30(7):1300-1316. [PubMed: 16022928]

Jurj AL, Wen WQ, Gao YT, Matthews CE, Yang G, Li HL, et al. Patterns and Correlates of Physical Activity: A Cross-Sectional Study in Urban Chinese. BMC Public Health. 2007; 7 Article Number 213.

Jusot F, Khlat M, Rochereau T, Sermet C. Job Loss from Poor Health, Smoking and Obesity: A National Prospective Survey in France. Journal of Epidemiology and Community Health. 2008; 62(4):332-337. [PubMed: 18339826]

Kendzor DE, Cofta-Woerpel LM, Mazas CA, Li Y, Vidrine JI, Reitzel LR, et al. Socioeconomic Status, Negative Affect, and Modifiable Cancer Risk Factors in African-American Smokers. Cancer Epidemiology, Biomarkers \& Prevention. 2008; 17(10):2456-2554.

Khan S, Murray RP, Barnes GE. A Structural Equation Model of the Effect of Poverty and Unemployment on Alcohol Abuse. Addictive Behaviors. 2002; 27(3):405-423. [PubMed: 12118628]

Kivimaki M, Vahtera J, Virtanen M, Elovainio M, Pentti J, Ferrie JE. Temporary Employment and Risk of Overall and Cause-Specific Mortality. American Journal of Epidemiology. 2003; 158:663668. [PubMed: 14507602]

Laitinen J, Ek E, Sovio U. Stress-Related Eating and Drinking Behavior and Body Mass Index and Predictors of This Behavior. Preventive Medicine. 2002; 34(1):29-39. [PubMed: 11749094]

Laitinen J, Power C, Ek E, Sovio U, Jarvelin MR. Unemployment and Obesity Among Young Adults in a Northern Finland 1966 Birth Cohort. International Journal of Obesity. 2002; 26(10):13291338. [PubMed: 12355341]

Lavis JN. Unemployment and Mortality: A Longitudinal Study in the United States, 1968-1992. McMaster University Centre for Health Economics and Policy Analysis Working Paper Series 98-5. June. 1998

Leino-Arjas P, Liira J, Mutanen P, Malmivaara A, Matikainen E. Predictors and Consequences of Unemployment Among Construction Workers: Prospective Cohort Study. British Medical Journal. 1999; 319(7210):600-605. [PubMed: 10473472]

Liira J, Leino-Arjas P. Predictors and Consequences of Unemployment in Construction and Forest Work During a 5-Year Follow-Up. Scandinavian Journal of Work, Environment \& Health. 1999; 25(1):42-49.

Lipsey, MW.; Wilson, DB. Practical Meta-Analysis. Sage; Thousand Oaks, CA: 2001.

Lundin A, Lundberg I, Hallsten L, Ottoson J, Hemmingsson T. Unemployment and Mortality: A Longitudinal Prospective Study on Selection and Causation in 49321 Swedish Middle-aged Men. Journal of Epidemiology and Community Health. 2010; 64(1):22-28. [PubMed: 19289388]

Manor O, Eisenbach Z, Israeli A, Friedlander Y. Mortality Differentials among Women: The Israel Longitudinal Mortality Study. Social Science \& Medicine. 2000; 51(8):1175-1188. [PubMed: 11037208]

Manor O, Eisenbach Z, Peritz E, Friedlander Y. Mortality Differentials among Israeli Men. American Journal of Public Health. 1999; 89(12):1807-1813. [PubMed: 10589307]

Martikainen PT. Unemployment and Mortality among Finnish Men 1981-85. British Medical Journal. 1990; 301:407-411. [PubMed: 2282395]

Martikainen PT, Maki N, Jantti M. The Effects of Unemployment on Mortality Following Workplace Downsizing and Workplace Closure: A Register-Based Follow-up Study of Finnish Men and Women during Economic Boom and Recession. American Journal of Epidemiology. 2007; 165(9): 1070-1075. [PubMed: 17363363]

Martikainen PT, Valkonen T. Excess Mortality of Unemployed Men and Women during a Period of Rapidly Increasing Unemployment. Lancet. 1996; 348:909-912. [PubMed: 8843808]

Masudomi I, Isse K, Uchiyama M, Watanabe H. Self-Help Groups Reduce Mortality Risk: A 5-Year Follow-up Study of Alcoholics in the Tokyo Metropolitan Area. Psychiatry and Clinical Neurosciences. 2004; 58(5):551-557. [PubMed: 15482588] 
Matoba T, Ishitake T, Noguchi R. A 2-year Follow-up Survey of Health and Lifestyle in Japanese Unemployed Persons. International Archives of Occupational and Environmental Health. 2003; 76(4):302-308. [PubMed: 12768282]

Merline AC, O'Malley PM, Schulenberg JE, Bachman JG, Johnston LD. Substance Use Among Adults 35 Years of Age: Prevalence, Adulthood Predictors, and Impact of Adolescent Susbtance Abuse. American Journal of Public Health. 2004; 94(1):96-102. [PubMed: 14713705]

Montgomery SM, Bartley MJ, Cook DG, Wadsworth MEJ. Health and Social Precursors of Unemployment in Young Men in Great Britain. Journal of Epidemiology and Community Health. 1996; 50(4):415-422. [PubMed: 8882225]

Montgomery SM, Cook DG, Bartley MJ, Wadsworth MEJ. Unemployment, Cigarette Smoking, Alcohol Consumption and Body Weigth in Young British Men. European Journal of Public Health. 1998; 8(1):21-27.

Moreno SG, Sutton AJ, Ades AE, Stanley TD, Abrams KR, Peters JL, et al. Assessment of Regression-based Methods to Adjust for Publication Bias through a Comprehensive Study. BMC Medical Research Methodology. 2009; 9(2)

Morrell S, Taylor R, Quine S, Kerr C, Western J. A Case-Control Study of Employment Status and Mortality in a Cohort of Australian Youth. Social Science \& Medicine. 1999; 49:383-392. [PubMed: 10414822]

Morrell SL, Taylor RJ, Kerr CB. Jobless: Unemployment and Young People's Health. Medical Journal of Australia. 1998; 168(5):236-240. [PubMed: 9539904]

Morris JK, Cook DG, Shaper AG. Nonemployment and Changes in Smoking, Drinking, and BodyWeight. British Medical Journal. 1992; 304(6826):536-541. [PubMed: 1559056]

Morris JK, Cook DG, Shaper AG. Loss of Employment and Mortality. British Medical Journal. 1994; 308:1135-1139. [PubMed: 8173455]

Mortished, C. Global unemployment heads towards 50 million. The Times Online; London: 2009.

Moser KA, Fox AJ, Jones DR. Unemployment and Mortality in the OPCS Longitudinal Study. The Lancet. 1984; 324(8415):1324-1329.

Moser KA, Fox AJ, Jones DR, Goldblatt PO. Unemployment and Mortality: Further Evidence from the OPCS Longitudinal Study 1971-81. The Lancet. 1986; 15:365-367.

Moser KA, Goldblatt PO, Fox AJ, Jones DR. Unemployment and Mortality: Comparison of the 1971 and 1981 Longitudinal Study Census Samples. British Medical Journal (Clinical Research Edition). 1987; 294:86-90.

Mossakowski KN. Is the Duration of Poverty and Unemployment a Risk Factor for Heavy Drinking. Social Science and Medicine. 2008; 67(6):947-955. [PubMed: 18573582]

Novo M, Hammarstrom A, Janlert U. Do High Levels of Unemployment Influence the Health of Those Who Are Not Unemployed? A Gendered Comparison of Young Men and Women During Boom and Recession. Social Science and Medicine. 2001; 53:293-303. [PubMed: 11439814]

Nylen L, Voss M, Floderus B. Mortality among Women and Men Relative to Unemployment, PartTime Work, Overtime Work, and Extra Work: A Study Based on Data from the Swedish Twin Registry. Occupational and Environmental Medicine. 2001; 58:52-57. [PubMed: 11119635]

Orth-Gomer, K.; Johnson, JV.; Unden, A-L.; Edwards, M-E. Social Interaction and Mortality in Sweden. Findings in the Normal Population and in Cardiovascular Patients. In: Isacsson, S-O.; Janzon, L., editors. Social Support - Health and Disease. Sixth International Berzelius Symposium. Almqvist \& Wiksell International; Stockholm: 1986. p. 21-31.

Palloni A, Arias E. Paradox Lost: Explaining the Hispanic Adult Mortality Advantage. Demography. 2004; 41(3):385-415. [PubMed: 15461007]

Paraponaris A, Saliba B, Ventelou B. Obesity, Weight Status and Employability: Empirical Evidence from a French National Survey. Economics and Human Biology. 2005; 3(2):241-258. [PubMed: 16005697]

Pensola TH, Martikainen P. Effects of Living Conditions in the Parental Home and Youth Paths on the Social Class Differences in Mortality among Women. Scandinavian Journal of Public Health. 2003; 31:428-438. [PubMed: 14675934]

Pensola TH, Martikainen P. Life-Course Experiences and Mortality by Adult Social Class among Young Men. Social Science \& Medicine. 2004; 58(11):2149-2170. [PubMed: 15047074] 
Peretti-Watel P, Constance J. 'It's All We Got Left'. Why Poor Smokers are Less Sensitive to Cigarette Price Increases. International Journal of Environmental Research and Public Health. 2009; 6(2):608-621. [PubMed: 19440404]

Peters JL, Sutton AJ, Jones DR, Abrams KR, Rushton L. Comparison of Two Methods to Detect Publication Bias in Meta-analysis. Journal of the American Medical Association. 2006; 295(6): 676-680. [PubMed: 16467236]

Regidor E, Calle ME, Dominguez V, Navarro P. Mortality by Social and Economic Characteristics: The Mortality Study of the Autonomous Community of Madrid, Spain. Medicina Clinica (Barcelona). 2001; 116(19):726-731.

Rehm J, Gmel G. Patterns of Alcohol Consumption and Social Consequences. Results from an 8-year Follow-up Study in Switzerland. Addiction. 1999; 94(6):899-912. [PubMed: 10665078]

Reine I, Novo M, Hammarstrom A. Does the Association Between Ill Health and Unemployment Differ Between Young People and Adults? Results from a 14-Year Follow-Up Study with a Focus on Psychological Health and Smoking. Public Health. 2004; 118(5):337-345. [PubMed: 15178140]

Robinson N, Lloyd CE, Stevens LK. Social Deprivation and Mortality in Adults with Diabetes Mellitus. Diabetic Medicine. 1998; 15:205-212. [PubMed: 9545121]

Rodriguez E, Chandra P. Alcohol, Employment Status, and Social Benefits: One More Piece of the Puzzle. American Journal of Drug and Alcohol Abuse. 2006; 32(2):237-259. [PubMed: 16595326]

Ruhm C. Are Recessions Good for Your Health? Quarterly Journal of Economics. 2000; 115(2):617650.

Salm M. Does Job Loss Cause Ill Health? Health Economics. 2009; 18(9):1075-1089. [PubMed: 19634153]

Singh GK, Siahpush M. All-Cause and Cause-Specific Mortality of Immigrants and Native Born in the United States. American Journal of Public Health. 2001; 91(3):392-399. [PubMed: 11236403]

Sorlie PD, Backlund E, Keller JB. U.S. Mortality by Economic, Demographic, and Social Characteristics - The National Longitudinal Mortality Study. American Journal of Public Health. 1995; 85(7):949-956. [PubMed: 7604919]

Sorlie PD, Rogot E. Mortality by Employment Status in the National Longitudinal Mortality Study. American Journal of Epidemiology. 1990; 132(5):983-992. [PubMed: 2239913]

Spence, NJ. Sociology. Florida State University; Tallahassee: 2006. Reproductive Patterns and Women's Later Life Health.

Stefansson C-G. Long-Term Unemployment and Mortality in Sweden, 1980-1986. Social Science \& Medicine. 1991; 32(4):419-423. [PubMed: 2024157]

Stock, WA. Systematic Coding for Research Synthesis. In: Cooper, HM.; Hedges, LV., editors. The Handbook of Research Synthesis. Vol. 236. Russell Sage Foundation; New York: 1994. p. 125-138.

Stuckler D, Basu S, Suhrcke M, Coutts A, McKee M. The Public Health Impact of Economic Crises and Alternative Policy Responses in Europe. Lancet. 2009; 374(9686):315-323. [PubMed: 19589588]

Temple MT, Fillmore KM, Hartka E, Johnstone B, Leino EV, Motoyoshi M. A Metaanalysis of Change in Marital and Employment Status as Predictors of Alcohol-Consumption on a Typical Occiasion. British Journal of Addiction. 1991; 86(10):1269-1281. [PubMed: 1836409]

Terrin N, Schmid CH, Lau J, Olkin I. Adjusting for Bias in the Presence of Heterogeneity. Statistics in Medicine. 2003; 22:2113-2126. [PubMed: 12820277]

Tsai SL, Lan CF, Lee CH, Huang N, Chou YJ. Involuntary Unemployment and Mortality in Taiwan. Journal of the Formosan Medical Association. 2004; 103:900-907. [PubMed: 15624038]

U.S. Bureau of Labor Statistics. International Unemployment Rates and Employment Indexes, Seasonally Adjusted, 2008-2010. 2010. http://www.bls.gov/fls/intl_unemployment_rates_monthly.htm, Accessed on April 7, 2010

United Nations News Centre. Global unemployment remains at historic high despite strong economic growth - UN. United Nations New Service; New York: 2007. 
United States Department of Labor. Economy at a Glance: United States -- Monthly Data. 2010. http://stats.bls.gov/eag/eag.us.htm, Accessed on September 29, 2010

Viinamaki H, Niskanen L, Koskela K. Factors Predicting Health Behavior. Nordic Journal of Psychiatry. 1997; 51(6):431-438.

Virtanen P, Vahtera J, Broms U, Sillanmaeki L, Kivimaeki M, Koskenvuo M. Employment Trajectory as Determinant of Change in Health-Related Lifestyle: The Prospective HeSsup Study. European Journal of Public Health. 2008; 18(5):504-508. [PubMed: 18515862]

Voss M, Nylen L, Floderus B, Diderichsen F, Terry PD. Unemployment and Early Cause-Specific Mortality: A Study Based on the Swedish Twin Registry. American Journal of Public Health. 2004; 94:2155-2161. [PubMed: 15569968]

Wadsworth MEJ, Montgomery SM, Bartley MJ. The Persisting Effect of Unemployment on Health and Social Well-Being in Men Early in Working Life. Social Science and Medicine. 1999; 48(10):1491-1499. [PubMed: 10369448]

Weden MM, Astone NM, Bishai D. Racial, Ethnic, and Gender Differences in Smoking Cessation Associated with Employment and Joblessness Through Young Adulthood in the U.S. Social Science and Medicine. 2006; 62(2):303-316. [PubMed: 16029919]

Weitoft GR, Haglund B, Rosen M. Mortality among Lone Mothers in Sweden: A Population Study. The Lancet. 2000; 355(9211):1215-1219.

Wells, GA.; Shea, B.; O'Connell, D.; Peterson, J.; Welch, V.; Losos, M., et al. The Newcastle-Ottawa Scale (NOS) for Assessing the Quality of Nonrandomized Studies in Meta-analysis. 2009. http://www.ohri.ca/programs/clinical_epidemiology/nosgen.pdf

Zhang J, Yu KF. What's the Relative Risk? A Method of Correcting the Odds Ratio in Cohort Studies of Common Outcomes. Journal of the American Medical Association. 1998; 280:1690-1691. [PubMed: 9832001] 


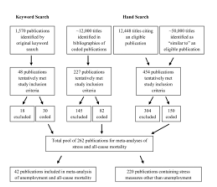

Figure 1.

Flow Diagram. 


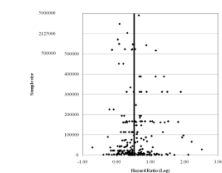

Figure 2.

Funnel plot of logarithmic hazard ratio vs. sample size. ${ }^{\mathrm{a}}$

${ }^{a}$ Vertical line denotes the mean log hazard ratio of 0.52 . To better show the dispersion of points, they axis-scale is less condensed from 0 to 500,000 and more condensed from 500,000 to $5,000,000$ 


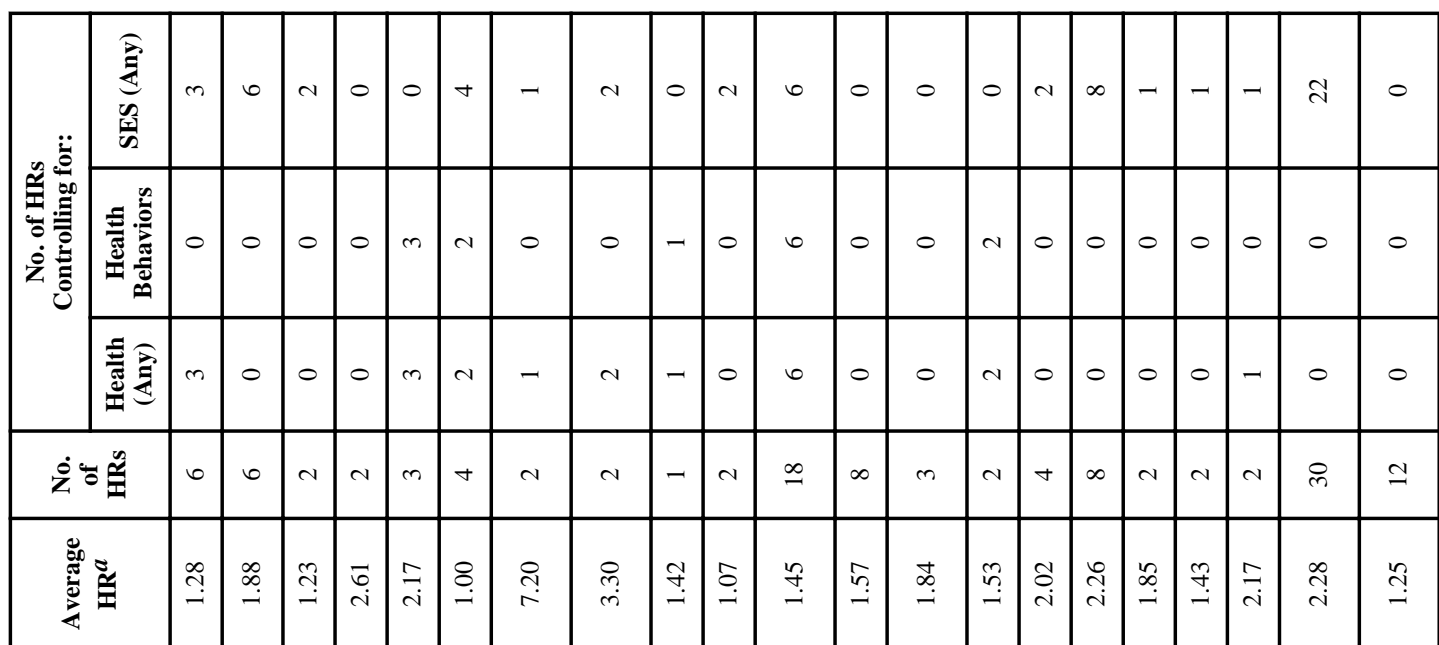

\begin{tabular}{|c|c|c|c|c|c|c|c|c|c|c|c|c|c|c|c|c|c|c|c|c|}
\hline 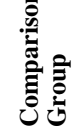 & 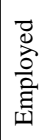 & 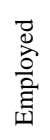 & 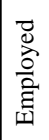 & 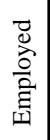 & 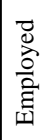 & 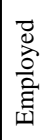 & 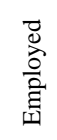 & $\begin{array}{l}\bar{\Delta} \\
\text { 흄 }\end{array}$ & 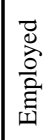 & 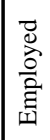 & 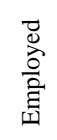 & 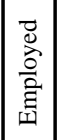 & 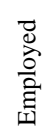 & 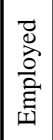 & 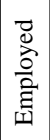 & & 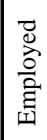 & 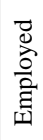 & 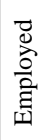 & 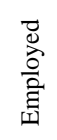 \\
\hline
\end{tabular}

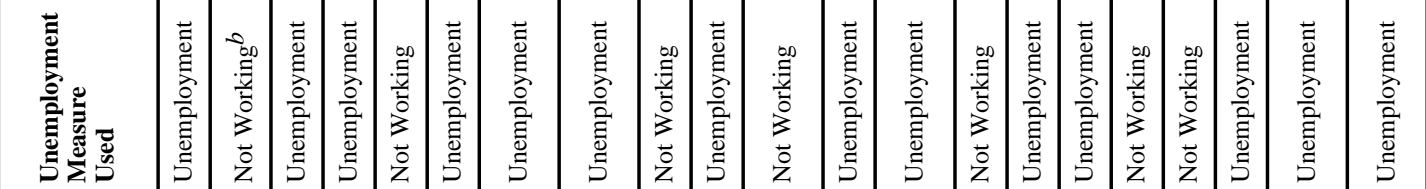

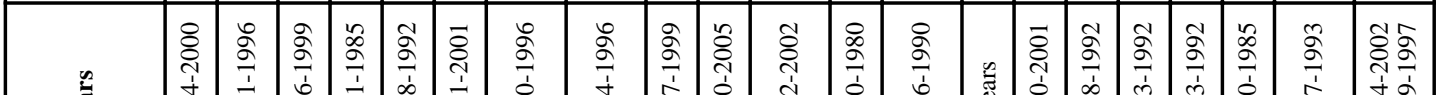

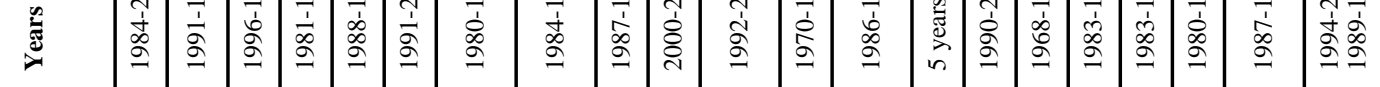

\begin{tabular}{|c|c|c|c|c|c|c|c|c|c|c|c|c|c|c|c|c|c|c|c|c|c|}
\hline 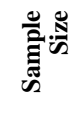 & $\begin{array}{l}\dot{\sigma} \\
\dot{q} \\
\end{array}$ & $\begin{array}{l}\text { बे } \\
\overline{\text { ले }}\end{array}$ & $\mid \begin{array}{l}8 \\
8 \\
0 \\
0 \\
0\end{array}$ & $\frac{ \pm}{n}$ & in & $n$ & $\begin{array}{l}+ \\
\text { aे } \\
\text { ते }\end{array}$ & శ్లి & & $\varnothing$ & $\begin{array}{l}\vec{\infty} \\
\stackrel{0}{=}\end{array}$ & 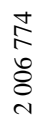 & $\stackrel{2}{2}$ & \begin{tabular}{|l}
$\infty$ \\
0 \\
0 \\
0
\end{tabular} & $\begin{array}{l}\bar{\sigma} \\
\tilde{\sigma} \\
\tilde{\sigma}\end{array}$ & $\begin{array}{l}\text { 某 } \\
\text { in }\end{array}$ & $\begin{array}{l}\hat{i} \\
\stackrel{i}{c} \\
i\end{array}$ & $\begin{array}{l}\overparen{6} \\
\stackrel{2}{2}\end{array}$ & $\mid \begin{array}{l}n \\
\tilde{n} \\
2 \\
\delta\end{array}$ & $\begin{array}{l}8 \\
8 \\
8 \\
0 \\
\sim\end{array}$ & $\begin{array}{l}\stackrel{2}{2} \\
\stackrel{2}{2}\end{array}$ \\
\hline
\end{tabular}

\begin{tabular}{|c|c|c|c|c|c|c|c|c|c|c|c|c|c|c|c|c|c|c|c|}
\hline & 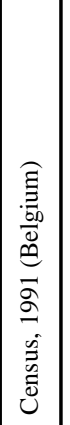 & 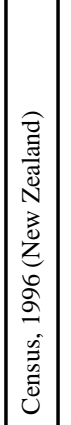 & 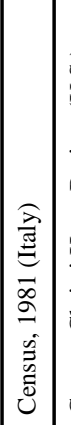 & 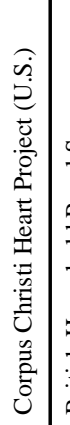 & 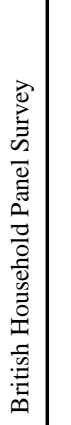 & 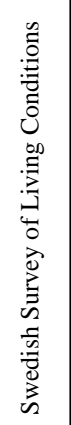 & 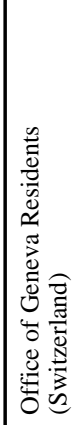 & 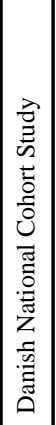 & 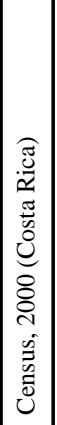 & 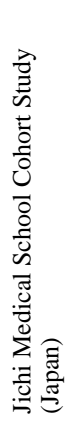 & 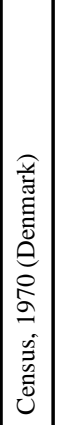 & 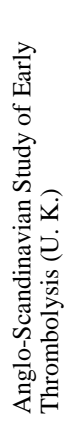 & 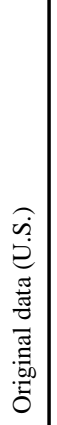 & 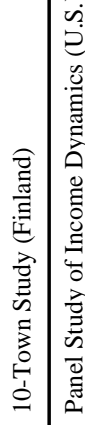 & 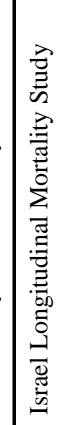 & 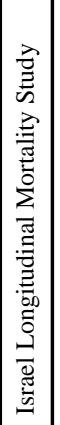 & 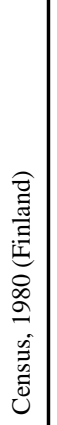 & 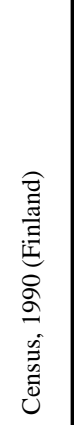 & \\
\hline 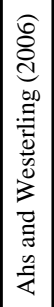 & 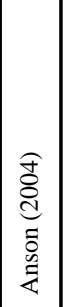 & 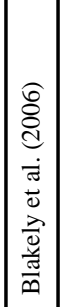 & 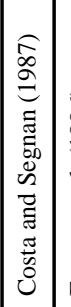 & 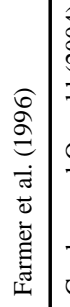 & 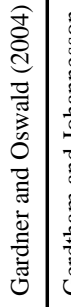 & 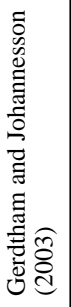 & 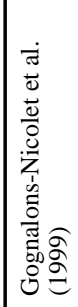 & 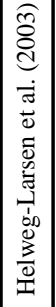 & 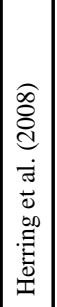 & 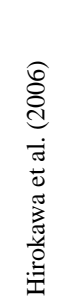 & 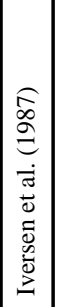 & 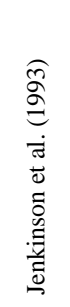 & 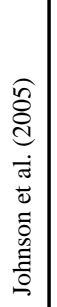 & 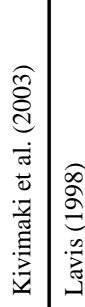 & 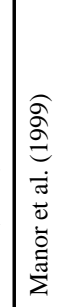 & 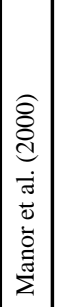 & 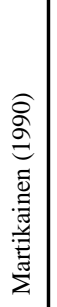 & 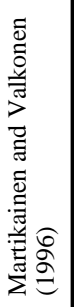 & \\
\hline
\end{tabular}




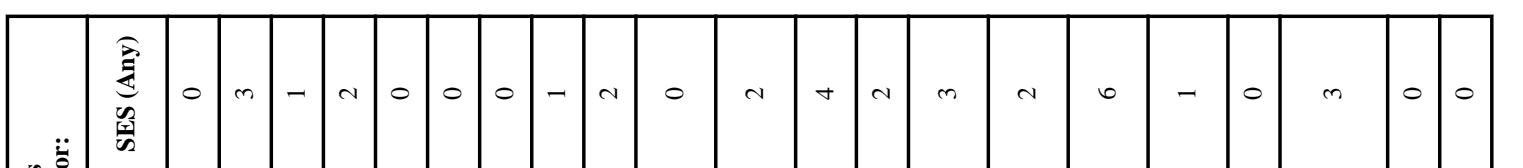

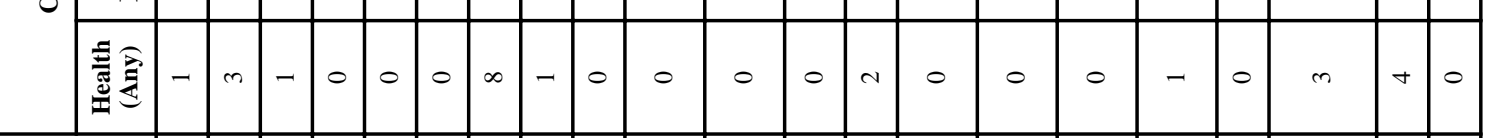

\begin{tabular}{|c|c|c|c|c|c|c|c|c|c|c|c|c|c|c|c|c|c|c|c|c|}
\hline$\dot{\dot{z}} \ddot{\underline{z}}$ & $\sim$ & in & $m$ & 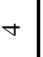 & t & r & $\underline{\simeq}$ & - & & N & 6 & $\infty$ & $\nabla$ & 0 & 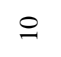 & $\simeq$ & - & 6 & $m$ & 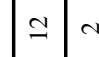 \\
\hline
\end{tabular}

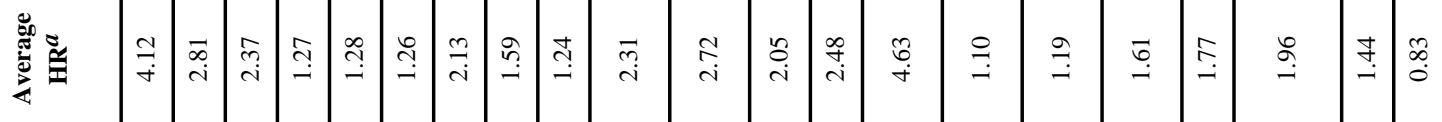

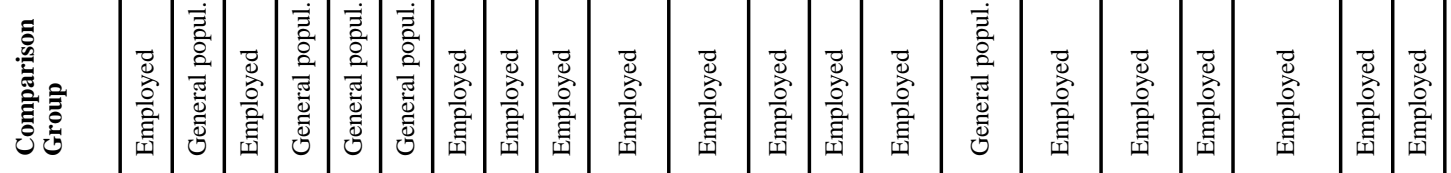

\begin{tabular}{|c|c|c|c|c|c|c|c|c|c|c|c|c|c|c|c|c|c|c|c|c|c|}
\hline 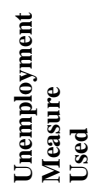 & 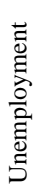 & 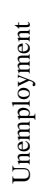 & 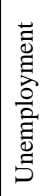 & 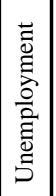 & 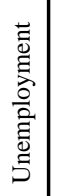 & 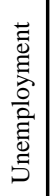 & 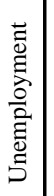 & 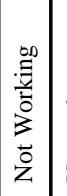 & 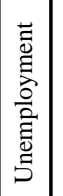 & 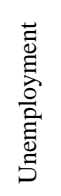 & 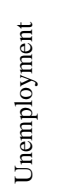 & 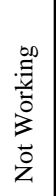 & 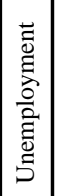 & 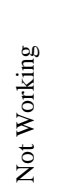 & $\widehat{\overrightarrow{0}}$ & $\begin{array}{l}\text { च. } \\
\text { हू. } \\
\frac{0}{0} \\
\overline{0} \\
\overline{0} \\
5\end{array}$ & 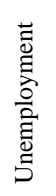 & 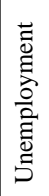 & $\begin{array}{l}\overrightarrow{\bar{\Xi}} \\
\bar{\Xi} \\
\bar{O} \\
\bar{\Xi} \\
\bar{\Xi}\end{array}$ & 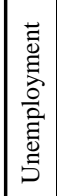 & \\
\hline$\frac{2}{\sigma}$ & $\frac{\partial}{\partial}$ & $\begin{array}{l}\infty \\
\approx \\
\frac{0}{f}\end{array}$ & $\begin{array}{l}\stackrel{2}{2} \\
\frac{1}{1} \\
\frac{0}{5} \\
\vdots\end{array}$ & 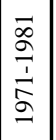 & 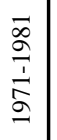 & 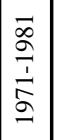 & 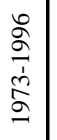 & $\begin{array}{l}\vec{\alpha} \\
\stackrel{0}{0} \\
\bar{b} \\
\vdots \\
a\end{array}$ & $\mid \begin{array}{l}\hat{a} \\
\stackrel{a}{1} \\
\approx \\
o\end{array}$ & $\begin{array}{l}\infty \\
\frac{\infty}{1} \\
\vdots \\
\circ\end{array}$ & $\begin{array}{l}\infty \\
\frac{\infty}{1} \\
\vdots \\
\frac{1}{2}\end{array}$ & 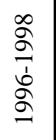 & 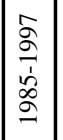 & $\begin{array}{l}\stackrel{a}{\stackrel{1}{7}} \\
\frac{1}{2}\end{array}$ & & $\begin{array}{l}\stackrel{a}{\circ} \\
\frac{1}{a} \\
\stackrel{5}{a}\end{array}$ & $\begin{array}{l}\overline{0} \\
\stackrel{1}{1} \\
\stackrel{1}{\circ} \\
\varrho\end{array}$ & & 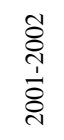 & $\mid \begin{array}{l}\stackrel{2}{2} \\
\stackrel{2}{1} \\
\stackrel{2}{2} \\
2\end{array}$ & \\
\hline \pm & $\stackrel{n}{m}$ & 5 & $\frac{\bar{\sigma}}{6}$ & 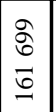 & $\begin{array}{l}a \\
\dot{0} \\
0 \\
0\end{array}$ & ڤิ & $\tilde{ర}$ & \begin{tabular}{|l|}
\multirow{0}{0}{} \\
D \\
$=$ \\
\end{tabular} & $\begin{array}{l}\text { t } \\
\dot{0} \\
\text { ले }\end{array}$ & $\begin{array}{l}\stackrel{0}{N} \\
\stackrel{\Xi}{\Xi}\end{array}$ & 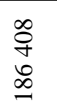 & $\bar{\Xi}$ & 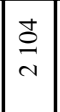 & $\frac{\infty}{\stackrel{\infty}{\vec{D}}}$ & & $n$ & $\infty$ & & & $\approx$ & \\
\hline
\end{tabular}

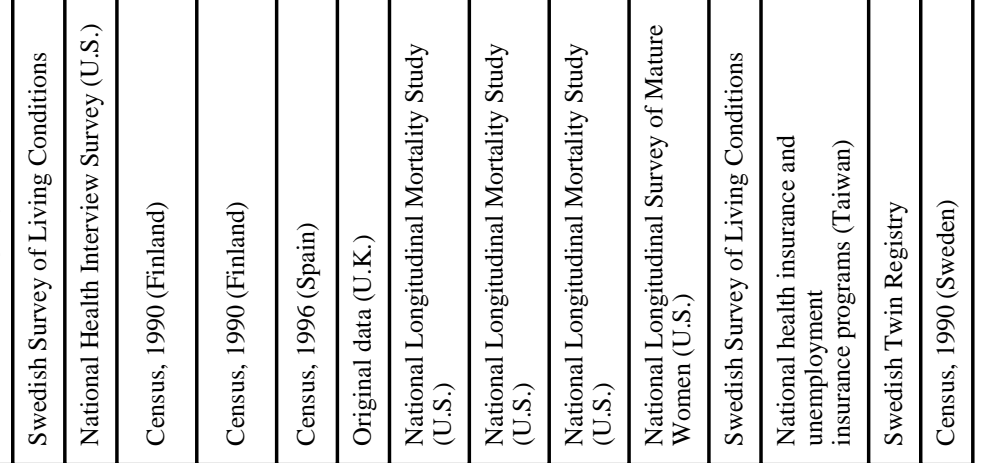


Table 2

Distribution of mortality risk estimates in the analysis by selected variables.

\begin{tabular}{|c|c|}
\hline Variable & Distribution $^{a}$ \\
\hline \multicolumn{2}{|l|}{ Publication date } \\
\hline 1980-1989 & 10.2 \\
\hline 1990-1999 & 38.3 \\
\hline $2000-2008$ & 51.5 \\
\hline \multicolumn{2}{|l|}{ Level of statistical adjustment } \\
\hline Unadjusted & 17.0 \\
\hline Adjusted for age only & 31.9 \\
\hline Adjusted for age and additional covariates & 51.1 \\
\hline \multicolumn{2}{|l|}{ Sex } \\
\hline Women only & 33.6 \\
\hline Men only & 47.2 \\
\hline Both & 19.2 \\
\hline \multicolumn{2}{|l|}{ Mean age of study sample at baseline (y) } \\
\hline$<40$ & 31.5 \\
\hline $40-49.9$ & 51.5 \\
\hline $50-64.9$ & 14.4 \\
\hline$\leq 65$ & 2.6 \\
\hline \multicolumn{2}{|l|}{ Baseline start year } \\
\hline $1960-1969$ & 2.1 \\
\hline $1970-1979$ & 35.7 \\
\hline $1980-1989$ & 33.4 \\
\hline $1990-2001$ & 28.8 \\
\hline \multicolumn{2}{|c|}{ Years elapsed between end of baseline and start of follow-up } \\
\hline 0 & 80.4 \\
\hline$>0$ & 19.6 \\
\hline \multicolumn{2}{|l|}{ Comparison group } \\
\hline Employed only & 91.1 \\
\hline General population & 8.9 \\
\hline \multicolumn{2}{|l|}{ Nation } \\
\hline Denmark, Finland, and Sweden & 46.7 \\
\hline United States & 18.7 \\
\hline United Kingdom & 11.5 \\
\hline Japan and Taiwan & 9.8 \\
\hline Belgium, Italy, Israel, Spain, and Switzerland & 9.5 \\
\hline Australia and New Zealand & 3.0 \\
\hline Costa Rica & 0.9 \\
\hline Maximum follow-up time (y): & \\
\hline
\end{tabular}




\begin{tabular}{|l|l|}
\hline Variable & Distribution $^{\boldsymbol{a}}$ \\
\hline First Quartile & 5.0 \\
\hline Median & 8.0 \\
\hline Third Quartile & 10.5 \\
\hline Death rate estimated? & \\
\hline Yes & 26.8 \\
\hline No & 73.2 \\
\hline Standard error estimated? & \\
\hline Yes & 10.2 \\
\hline No & 89.8 \\
\hline Mean Newcastle-Ottawa Scale Rating & 7.76 \\
\hline
\end{tabular}

${ }^{a}$ Values are percentages unless indicated otherwise, $\mathrm{n}=235$ hazard ratios. 
Table 3

Meta-analyses. ${ }^{a}$

\begin{tabular}{|c|c|c|c|}
\hline Data & Unadjusted & $\begin{array}{l}\text { Adjusted for } \\
\text { Age Only }\end{array}$ & $\begin{array}{c}\text { Adjusted for } \\
\text { Age and } \\
\text { Additional Covariates } b\end{array}$ \\
\hline All available data & $2.08(1.77,2.43)$ & $1.59(1.42,1.77)$ & $1.63(1.49,1.79)$ \\
\hline Nonestimated death rate only & $2.04(1.73,2.40)$ & $1.48(1.30,1.68)$ & $1.66(1.48,1.86)$ \\
\hline Nonestimated standard error only & $2.08(1.77,2.43)$ & $1.67(1.48,1.89)$ & $1.69(1.54,1.85)$ \\
\hline \multicolumn{4}{|l|}{ Sex } \\
\hline Women only & $1.62(1.25,2.09)$ & $1.31^{c}(1.10,1.56)$ & $1.37(1.17,1.60)$ \\
\hline Men only & $2.38(1.85,3.08)$ & $1.79(1.56,2.05)$ & $1.78(1.56,2.02)$ \\
\hline \multicolumn{4}{|l|}{ Average age (y) } \\
\hline$<40$ & $1.84(1.37,2.48)$ & $1.66(1.39,1.97)$ & $1.73(1.41,2.11)$ \\
\hline $40-49.9$ & $2.25(1.87,2.71)$ & $1.77(1.51,2.08)$ & $1.77(1.59,1.98)$ \\
\hline $50-65$ & $1.64^{e}(0.97,2.76)$ & $1.33^{d}(1.02,1.74)$ & $1.25^{d}(1.03,1.52)$ \\
\hline \multicolumn{4}{|l|}{ Mean follow-up duration (y) } \\
\hline$\leq 5$ & $1.70^{c}(1.15,2.52)$ & $1.50(1.26,1.80)$ & $1.73(1.44,2.06)$ \\
\hline $5.1-10$ & $2.65(2.15,3.25)$ & $1.83(1.55,2.15)$ & $1.76(1.55,2.00)$ \\
\hline$>10$ & $1.58(1.22,2.04)$ & $1.37^{c}(1.12,1.67)$ & $1.42(1.22,1.64)$ \\
\hline \multicolumn{4}{|l|}{ Comparison group } \\
\hline Employed & $2.09(1.79,2.45)$ & $1.75(1.54,1.98)$ & $1.63(1.50,1.78)$ \\
\hline General Population & $\ldots$ & $1.24^{d}(1.01,1.51)$ & $\cdots$ \\
\hline \multicolumn{4}{|l|}{ Unemployment measure } \\
\hline Unemployed only & $1.75(1.48,2.08)$ & $1.58(1.41,1.77)$ & $1.60(1.45,1.76)$ \\
\hline Unemployed or not in labor force & $3.76(2.75,5.14)$ & $1.62(1.25,2.10)$ & $1.73(1.46,2.04)$ \\
\hline
\end{tabular}

${ }^{a}$ All meta-analyses were calculated by maximum likelihood using a random effects model. See Table 4 for information on sample sizes for each analysis. Values are presented as mean hazard ratio (95\% confidence interval). Unless indicated otherwise $\mathrm{p} \leq .001$. Ellipses indicate situations where $\mathrm{n} \leq 1$ and meaningful mean HR could not be calculated.

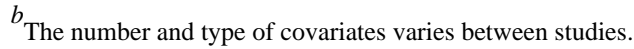

$c_{\mathrm{p}} \leq .01$.

$d_{\mathrm{p} \leq .05}$.

$e_{\mathrm{p}}>.05$. 


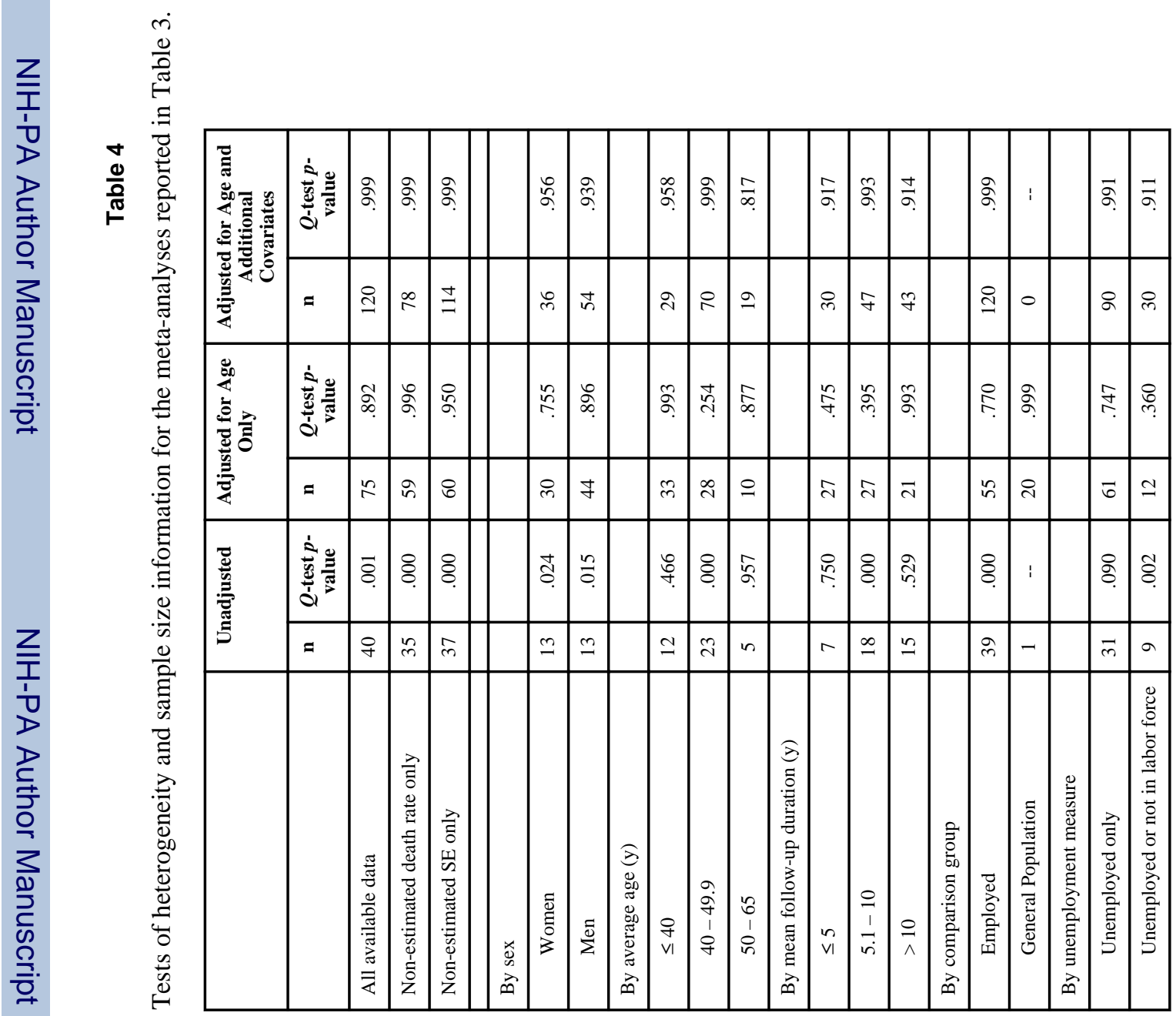


Table 5

Bivariate and multivariate meta-regression analyses predicting the magnitude of the effect of unemployment on mortality. ${ }^{a}$

\begin{tabular}{|c|c|c|c|}
\hline Variable & $\begin{array}{l}\text { Multivariate } \\
\text { Model } 1\end{array}$ & $\begin{array}{l}\text { Multivariate } \\
\text { Model 2 }\end{array}$ & $\begin{array}{l}\text { Parsimonious } \\
\quad \text { Model } b\end{array}$ \\
\hline Death rate estimated? (1, Yes; 0, No $)$ & $1.00(0.44,2.80)$ & $1.00(0.86,1.18)$ & $\ldots$ \\
\hline Standard error estimated? $(1$, Yes; 0, No $)$ & $0.84(0.64,1.08)$ & $0.83(0.64,1.08)$ & $\ldots$ \\
\hline Proportion of sample that is male ( 0 to 1 ) & $1.35^{c}(1.18,1.54)$ & $1.35^{c}(1.19,1.54)$ & $1.37^{c}(1.21,1.56)$ \\
\hline Mean age of study sample at baseline (Reference group, $<40$ ) & $\ldots$ & $\ldots$ & $\ldots$ \\
\hline 40 to 49.9 & $0.99(0.83,1.18)$ & $0.99(0.83,1.18)$ & $1.06(0.92,1.22)$ \\
\hline 50 to 65 & $0.70^{d}(0.56,0.87)$ & $0.70^{c}(0.56,0.86)$ & $0.74^{d}(0.61,0.89)$ \\
\hline Study age (per 10 y) & $1.02(0.93,1.13)$ & $1.02(0.92,1.13)$ & $\ldots$ \\
\hline Years between end of baseline and start of follow-up & $1.06^{d}(1.02,1.10)$ & $1.05^{d}(1.01,1.10)$ & $1.06^{c}(1.03,1.10)$ \\
\hline Years between end of baseline and end of follow-up & $0.99(0.97,1.01)$ & $0.99(0.97,1.01)$ & $\ldots$ \\
\hline Comparison group (1, General population; 0 , Employed persons) & $0.67^{d}(0.50,0.88)$ & $0.66^{d}(0.50,0.87)$ & $0.68^{c}(0.55,0.83)$ \\
\hline Unemployment measure ( 1 , Any non-working; 0 , Unemployed only) & $1.49^{c}(1.23,1.79)$ & $1.51^{c}(1.25,1.82)$ & $1.46^{c}(1.27,1.69)$ \\
\hline Region (Reference group, Other developed nations) & $\cdots$ & $\cdots$ & $\ldots$ \\
\hline United States & $1.02(0.82,1.28)$ & $1.03(0.83,1.29)$ & $\ldots$ \\
\hline Scandinavia & $1.00(0.78,1.27)$ & $1.01(0.79,1.29)$ & $\ldots$ \\
\hline Controlled for sex (1, Yes; 0, No) & $0.89(0.71,1.11)$ & $0.87(0.70,1.09)$ & $\ldots$ \\
\hline Controlled for age $(1$, Yes; 0, No) & $0.83^{e}(0.70,0.97)$ & $0.84^{e}(0.72,0.99)$ & $0.84^{e}(0.72,0.97)$ \\
\hline Controlled for socioeconomic status (Reference group, No controls) & $\ldots$ & $\ldots$ & $\ldots$ \\
\hline Controlled for only education or only income ( 1 , Yes; 0, No) & $1.48(0.99,2.23)$ & $1.24(0.87,1.77)$ & $1.17(0.87,1.58)$ \\
\hline Controlled for two or more SES measures (1, Yes; 0 , No) & $0.87(0.76,1.00)$ & $0.87^{e}(0.75,1.00)$ & $0.87^{e}(0.77,0.98)$ \\
\hline Controlled for health & $\ldots$ & $\ldots$ & $\ldots$ \\
\hline Controlled for any health status variable ( 1 , Yes; 0, No) & $0.84(0.67,1.05)$ & $\ldots$ & $\ldots$ \\
\hline Controlled for health behaviors specifically ( 1 , Yes; 0 , No) & $\ldots$ & $0.75^{e}(0.58,0.96)$ & $0.76^{e}(0.60,0.95)$ \\
\hline Log of sample size & $1.01(0.97,1.05)$ & $1.00(0.96,1.04)$ & $\ldots$ \\
\hline Newcastle-Ottawa quality rating & $1.05(0.96,1.14)$ & $1.05(0.96,1.14)$ & $\ldots$ \\
\hline Constant & 1.11 & 1.25 & $1.62^{c}$ \\
\hline$R^{2}$ & .3875 & .3974 & .3702 \\
\hline Unexplained Heterogeneity Variance Component & $.0972^{c}$ & $.0959^{c}$ & $.1017^{c}$ \\
\hline
\end{tabular}

${ }^{a}$ All meta-regressions were calculated by maximum likelihood using a random effects model. $\mathrm{N}=235$ hazard ratios for all analyses. Numbers reported are the exponentiated regression coefficients (exponentiated 95\% confidence intervals). Ellipses indicate situations when a variable was not entered into a model.

${ }^{b}$ Obtained using backwards elimination, variables removed if $\mathrm{p}>.10$.

$c_{\mathrm{p}<.001}$

$d_{\mathrm{p}<.01}$

Soc Sci Med. Author manuscript; available in PMC 2012 March 1. 
$e_{\mathrm{p}} \leq .05$ 
Table 6

Meta-analyses stratified by gender and age ${ }^{a}$

\begin{tabular}{|l|l|l|l|l|}
\hline Gender & Mean Age & HR $(\mathbf{9 5 \%}$ CI $)$ & $\mathbf{n}$ & $\boldsymbol{Q}$-test $\boldsymbol{p}$-value \\
\hline \multirow{4}{*}{ Women } & Less than 40 & $1.73^{b}(1.41,2.11)$ & 19 & 0.937 \\
\cline { 2 - 6 } & 40 to 49.9 & $1.34^{b}(1.15,1.56)$ & 14 & 0.233 \\
\cline { 2 - 6 } & 50 to 65 & $0.94(0.80,1.11)$ & 9 & 0.999 \\
\hline \multirow{4}{*}{ Men } & Less than 40 & $1.95^{b}(1.69,2.26)$ & 26 & 0.398 \\
\cline { 2 - 6 } & 40 to 49.9 & $1.86^{b}(1.63,2.12)$ & 14 & 0.842 \\
\cline { 2 - 6 } & 50 to 65 & $1.17^{c}(1.00,1.36)$ & 11 & 0.365 \\
\hline
\end{tabular}

${ }^{a}$ Analyses based on 93 hazard ratios that were statistically-adjusted for age or had an age range smaller or equal to 35 years, did not use the general population as the control group, did not include persons not in the labor force in the case group, and were from studies with less than a one year gap between the end of baseline and the beginning of follow-up.

${ }_{\mathrm{p}<.001}$

${ }_{\mathrm{p}<.05}$ 
Table A1

Illustration of adjustments made to the inverse variance weights to correct for double reporting.

\begin{tabular}{|l|l|l|l|l|}
\hline $\begin{array}{l}\text { Author, Publication } \\
\text { Year }\end{array}$ & Gender & Age & $\begin{array}{l}\text { Original Inverse } \\
\text { Variance Weight }\end{array}$ & $\begin{array}{l}\text { Corrected } \\
\text { Inverse Variance } \\
\text { Weight }\end{array}$ \\
\hline Study X & Men only & All ages & 4 & 4 \\
\hline Study X & Women only & All ages & 2 & 2 \\
\hline Study Y & Men only & $20-44$ & 5 & 5 \\
\hline Study Y & Men only & $45-65$ & 7 & 7 \\
\hline Study Y & Men only & $65+$ & 3 & 3 \\
\hline Study Z & Men only & All ages & 12 & 6 \\
\hline Study Z & Women only & All ages & 20 & 10 \\
\hline Study Z & Both men \& women & $20-44$ & 16 & 8 \\
\hline Study Z & Both men \& women & $45-65$ & 24 & 12 \\
\hline Study Z & Both men \& women & $65+$ & 16 & 8 \\
\hline
\end{tabular}

